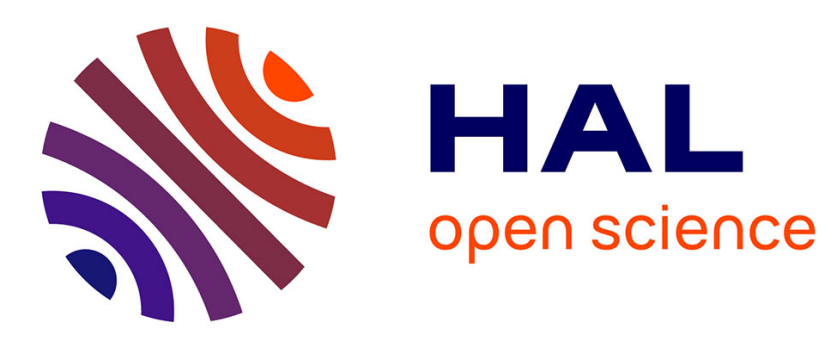

\title{
Predictability of Decadal Atlantic Meridional Overturning Circulation Variations
}

\author{
Florian Sévellec, Bablu Sinha
}

\section{To cite this version:}

Florian Sévellec, Bablu Sinha. Predictability of Decadal Atlantic Meridional Overturning Circulation Variations. Oxford Encyclopedia of Climate Science, Oxford University Press, Oxford University Press, 2018, 10.1093/acrefore/9780190228620.013.81 . hal-02136510

\section{HAL Id: hal-02136510 https://hal.science/hal-02136510}

Submitted on 22 May 2019

HAL is a multi-disciplinary open access archive for the deposit and dissemination of scientific research documents, whether they are published or not. The documents may come from teaching and research institutions in France or abroad, or from public or private research centers.
L'archive ouverte pluridisciplinaire HAL, est destinée au dépôt et à la diffusion de documents scientifiques de niveau recherche, publiés ou non, émanant des établissements d'enseignement et de recherche français ou étrangers, des laboratoires publics ou privés. 


\section{Oxford Research Encyclopedia of Climate Science}

\section{Predictability of Decadal Atlantic Meridional Overturning Circulation Variations a}

Florian Sévellec and Bablu Sinha

Subject: Climate Systems and Climate Dynamics, Modeling

Online Publication Date: Sep 2018 DOI: 10.1093/acrefore/9780190228620.013.81

\section{Summary and Keywords}

The Atlantic meridional overturning circulation (AMOC) is a large, basin-scale circulation located in the Atlantic Ocean that transports climatically important quantities of heat northward. It can be described schematically as a northward flow in the warm upper ocean and a southward return flow at depth in much colder water. The heat capacity of a layer of $2 \mathrm{~m}$ of seawater is equivalent to that of the entire atmosphere; therefore, ocean heat content dominates Earth's energy storage. For this reason and because of the AMOC's typically slow decadal variations, the AMOC regulates North Atlantic climate and contributes to the relatively mild climate of Europe. Hence, predicting AMOC variations is crucial for predicting climate variations in regions bordering the North Atlantic.

Similar to weather predictions, climate predictions are based on numerical simulations of the climate system. However, providing accurate predictions on such long timescales is far from straightforward. Even in a perfect model approach, where biases between numerical models and reality are ignored, the chaotic nature of AMOC variability (i.e., high sensitivity to initial conditions) is a significant source of uncertainty, limiting its accurate prediction. 


\section{Predictability of Decadal Atlantic Meridional Overturning Circulation Variations}

Predictability studies focus on factors determining our ability to predict the AMOC rather than actual predictions. To this end, processes affecting AMOC predictability can be separated into two categories: processes acting as a source of predictability (periodic harmonic oscillations, for instance) and processes acting as a source of uncertainty (small errors that grow and significantly modify the outcome of numerical simulations). To understand the former category, harmonic modes of variability or precursors of AMOC variations are identified. On the other hand, in a perfect model approach, the sources of uncertainty are characterized by the spread of numerical simulations differentiated by the application of small differences to their initial conditions. Two alternative and complementary frameworks have arisen to investigate this spread. The pragmatic framework corresponds to performing an ensemble of simulations, by imposing a randomly chosen small error on the initial conditions of individual simulations. This allows a probabilistic approach and to statistically characterize the importance of the initial condition by evaluating the spread of the ensemble. The theoretical framework uses stability analysis to identify small perturbations to the initial conditions, which are conducive to significant disruption of the AMOC.

Beyond these difficulties in assessing the predictability, decadal prediction systems have been developed and tested through a range of hindcasts. The inherent difficulties of operational forecasts span from developing efficient initialization methods to setting accurate radiative forcing to correcting for model drift and bias, all these improvements being estimated and validated through a range of specifically designed skill metrics.

Keywords: Atlantic meridional overturning circulation, North Atlantic, decadal predictability, decadal variability, interannual to decadal prediction

\section{Introduction}

In the context of the global warming, there is a growing societal demand to predict changes on interannual to decadal timescales to inform mitigation and adaptation strategy (IPCC, 2013). Whereas on multidecadal timescales the long secular warming trend dominates the global average surface atmospheric temperature (SAT), on interannual to decadal timescales, "internal" or "intrinsic" variability, generated from the internal dynamics of the climate system rather than external forcing, is the most important factor (more than $80 \%$ of the total variance for 10-year timescales; Figure 1, left). This result has also been suggested by Hawkins and Sutton (2009B) and Meehl et al. (2009), for instance, and implies that an accurate prediction of climate changes on interannual to decadal timescales is not strongly dependent on $\mathrm{CO}_{2}$ emission scenarios, but on "natural"1 variability of the climate system. 


\section{Predictability of Decadal Atlantic Meridional Overturning Circulation Variations}

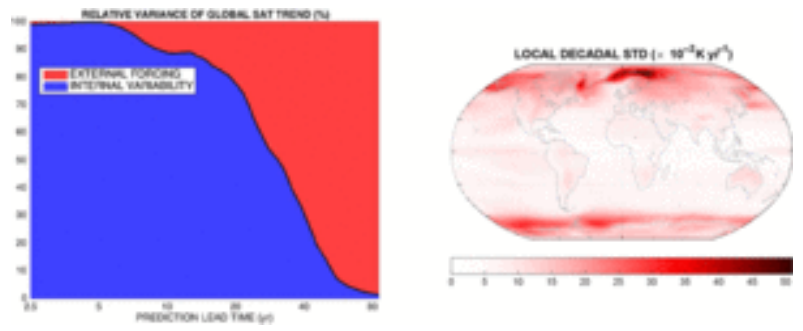

Click to view larger

Figure 1. Left: Relative contribution to the total variance of (red) external forcing and (blue) internal variability for the globally averaged surface atmospheric temperature (SAT) trend. The external forcing is assessed through the variance of multimodel means across four representative concentration pathway (RCP) scenarios from CMIP5 (RCP 2.6, 4.5, 6.0, and 8.5) at different lead times. The internal variability is assessed through the variance of the multimodel mean distribution filtered at different timescales, from CMIP5 preindustrial control simulations. Right: Multimodel mean of local standard deviation of SAT decadal trend from CMIP5 preindustrial control simulations.

If one focuses on internal variability for decadal and longer timescales, the surface temperature shows an intensified level of variability in the North Atlantic, and in particular in the Nordic Seas (Figure 1 , right). This signature is typical of changes in the Atlantic meridional overturning circulation (AMOC) on decadal timescales (Drijfhout, 2015; Vellinga \& Wood, 2002). Also, AMOC changes have been shown to lead to, or at least to be concomitant with, cooling of the North Atlantic ocean surface (Drijfhout, van Oldenborgh, \& Cimatoribus, 2012; Rahmstorf et al., 2015). So predicting AMOC variations is of firstorder importance for predicting the North Atlantic surface temperature.

From a physical oceanographic perspective, the AMOC is a basin-scale ocean circulation transporting heat poleward in the North Atlantic (Gordon, 1986; Stommel, 1958). This heat transport is achieved through a northward flow of relatively warm water in the upper $\sim 1,000 \mathrm{~m}$ and a southward flow of relatively cold water at depth. During its poleward journey the surface water exchanges heat with the atmosphere, cooling the surface ocean and warming the surface atmosphere. This warming influences the climate of the North Atlantic and bordering regions, through changes in tropical cyclone activity (Goldenberg et al., 2001), storminess over Europe (Jackson et al., 2015), precipitation over America (Enfield, Mestas-Nunez, \& Trimble, 2001), and African Sahel rainfall (Knight, Folland, \& Scaife, 2006), for instance.

The AMOC has been monitored at $26^{\circ} \mathrm{N}$ since 2004 (McCarthy et al., 2012; Srokosz et al., 2012; Srokosz \& Bryden, 2015). Interannual changes in the AMOC have been suggested to explain the severe winter conditions over northwestern Europe in 2010-2011 and the high-intensity hurricane season in summer 2010 (Bryden et al., 2014). These observational results are consistent with state-of-the-art climate modeling studies that have demonstrated AMOC influences on surface atmospheric pressure, SAT, or rainfall patterns on much longer timescales (Knight et al., 2005; Msadek \& Frankignoul, 2009; Sutton \& Hodson, 2003, 2005).

Hence, beyond the successful monitoring of the AMOC, predicting AMOC changes is essential to predict climate changes on decadal timescales. However, as with many complex systems, AMOC variations are neither regular nor characterized by a well- 


\section{Predictability of Decadal Atlantic Meridional Overturning Circulation Variations}

defined period, so predicting future evolution of AMOC is far from straightforward. Indeed, its evolution is typical of chaotic systems (Strogatz, 1994), meaning that the evolution of the AMOC is highly sensitive to its initial state, and a small error in specifying the initial state might have a significant effect in its predicted future evolution. ${ }^{2}$ Hence, it is of the utmost importance to determine AMOC predictability (i.e., the fundamental limits on our ability to predict it), as an essential precursor to, and theoretical underpinning of, actual prediction systems. To further define the difference between predictability studies and actual prediction, we can make the analogy with mathematics: predictability is to prediction as the existence of a solution is to the solution in mathematical problems.

This article uses two conceptual models to illustrate the limits of prediction under stochastic and deterministic chaos. In the context of the AMOC, the two types of chaos represent synoptic chaotic atmospheric variability forcing the ocean at its surface and internal chaotic variability, respectively. In the real world, both are active and may exert feedback on each other. Beyond considering these conceptual approaches, the article also describes the state-of-the art knowledge of AMOC predictability, by describing both contributing and limiting factors. In a more applied framework, existing prediction systems for interannual to decadal timescales and their current limits are discussed.

The article ignores a few factors that have an impact on the variability, and hence on the predictability, of the AMOC. For example, there is no discussion of the effects of solar cycles that are highly predictable and pace the climate system. The effect of volcanic eruptions or solar eruptions is also ignored, although these factors are potentially important to set up the AMOC variability (Swingedouw et al., 2015). In the same way, changes in the geographical location and strength of anthropogenic aerosol sources are not covered. These effects are unpredictable from a natural science point of view (either due to their random nature or because they are linked to socioeconomic changes), and they are assumed to be specified as part of future scenarios. However, these effects are fully acknowledged and discussed in the description of state-of-the-art prediction systems.

The article begins by developing two conceptual perspectives on AMOC predictability. Next, studies on predictability of the AMOC on decadal timescales are discussed. This is followed by a description of state-of-the-art prediction systems. The article concludes with a short discussion and directions for future work.

\section{Conceptual Perspectives}

The conceptual perspectives on AMOC predictability use two idealized models to illustrate the conceptual principles of predictability studies. The two models employ two different frameworks used to study and understand the growth of small disturbances (i.e., chaotic behavior). In the stochastic framework, the noise set as external forcing gives rise 


\section{Predictability of Decadal Atlantic Meridional Overturning Circulation Variations}

to divergence between model simulations. In the deterministic framework, nonlinearities of the system dynamics lead to divergence. Hence, the two frameworks schematically represent the two sources of uncertainty: external and internal, respectively.

\section{Stochastic Framework}

The first model describes the evolution of anomalous sea-surface temperature (SST) when subjected to stochastic forcing representing the intrinsic chaotic synoptic dynamics of the atmosphere. Hence the ocean model is forced by an ensemble of randomly selected anomalous SAT conditions. This model and framework are equivalent to the studies of Hasselmann (1976) and Frankignoul and Hasselmann (1977) in the context of ocean variability, and Chang et al. (2004) in the context of predictability.

The model reads:

$$
\partial_{t} \mathrm{SST}_{i}=\left(\mathrm{SAT}_{i}-\mathrm{SST}_{i}\right) / \tau
$$

(1)

where $\mathrm{SST}_{i}$ is the i-th realization of anomalous SST (Figure 2, top), $\mathrm{SAT}_{i}$ is the i-th realization of anomalous SAT, and $\tau$ is an oceanic adjustment timescale (set to 10 years in numerical applications). It is assumed that the SAT follows a white-noise distribution $\left(\left\langle S A T_{i} S A T_{j}\right\rangle\right)=\sigma_{0}^{2} \delta_{i, j}$, where $\delta_{i, j}$ is the Kronecker delta, $\sigma_{0}^{2}$ is the SAT standard deviation, set to $1.6 \mathrm{~K}$ in numerical applications, and angle brackets denote a time average.
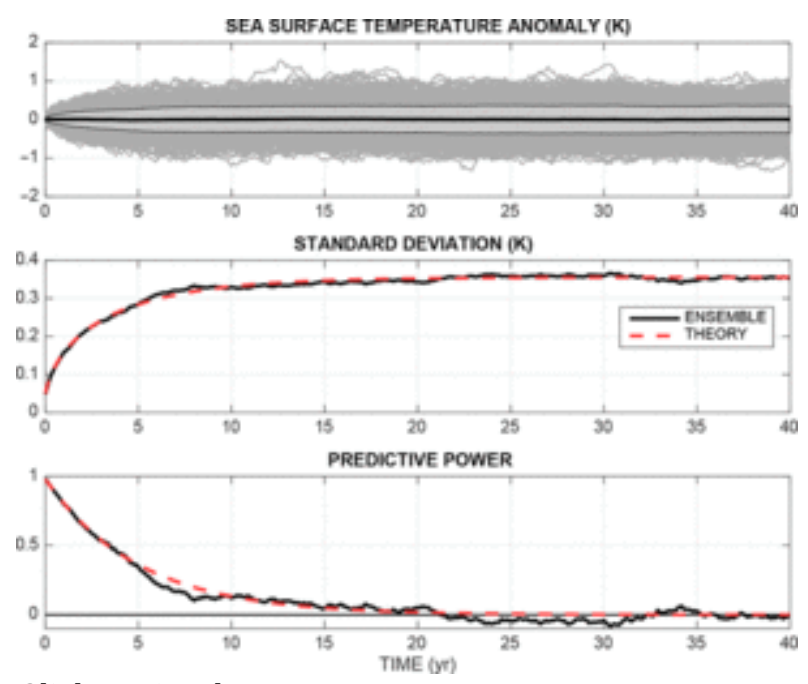

Click to view larger

Figure 2. (From top to bottom) Sea-surface temperature anomaly, standard deviation, and predictive power for the ensemble of 1,000 members (i.e., 1,000 different stochastic realizations) of the idealized stochastic model. The ensemble results (black solid lines) converge toward the theoretical results (red dashed lines) with increasing ensemble size (i.e., numbers of members/realizations; $\mathrm{cf}$. Figure 5).
This idealized model of a Langevin equation has a solution of the form of an Ornstein-Uhlenbeck process (see, e.g., section 3.4 in Dijkstra, 2013). Thus we can obtain the oceanic variance $\left(\sigma^{2}\right.$; Figure 2 , middle) as:

$$
\sigma^{2}(t)=\sigma_{\infty}^{2}\left(1-e^{-\frac{2 t}{\tau}}\right)
$$

where $\sigma_{\infty}^{2}$ is the asymptotic oceanic variance. Hence, using a Taylor expansion, we find the useful property that, on short timescales ( $t \ll \tau$ ), the variance grows linearly with time and is 
fully independent of the system dynamics:

$$
\sigma^{2}(t) \propto t, \text { for } t / \tau \ll 1
$$

(3)

This result can be generalized to any linear system, as shown by Chang et al. (2004) consistently with Hasselmann (1976).

Following Schneider and Griffies (1999), we define the predictive power (PP; Figure 2, bottom), bounded between 0 and 1 , which reads:

$$
P P(t)=1-\frac{\sigma^{2}(t)}{\sigma_{\infty}^{2}}=e^{-2 t / \tau}
$$

(4)

This suggests that the predictability of this idealized model in a stochastic framework is solely set by the typical damping rate, $\tau$, of the ocean adjustment. Chang et al. (2004) have demonstrated that this result is unchanged by the presence of oscillatory behavior or non-normality (despite the increase of the variance in the latter case; Ioannou, 1995). 


\section{Predictability of Decadal Atlantic Meridional Overturning Circulation Variations}

\section{Deterministic Framework}

This framework uses a different model. In this new model, the chaotic dynamics are generated internally by nonlinearities of the system. The model is a modification of the Howard-Malkus loop (Howard, 1971; Malkus, 1972; Welander, 1957, 1965, 1967), analogous to the waterwheel model (Dewar \& Huang, 1995, 1996; Huang \& Dewar, 1996; Strogatz, 1994), and representing AMOC dynamics (Sévellec \& Fedorov, 2014, 2015B). This model reads:

$$
d_{t} \omega=-\lambda \omega-\epsilon \beta S_{N S}
$$

(5a)

$$
d_{t} S_{B T}=\left(\Omega_{0}+\omega\right) S_{N S}-K S_{B T}+\frac{F_{0} S_{0}}{h}
$$

(5b)

$$
d_{t} S_{N S}=-\left(\Omega_{0}+\omega\right) S_{B T}-K S_{N S}
$$

(5c)

The three model variables are the varying component of the ocean meridional overturning $(\omega)$ and the vertical (Bottom-Top) and meridional (North-South) salinity gradients $\left(S_{B T}\right.$ and $S_{N S}$, respectively), each depending on time $(t)$. Here the circulation is the sum of a steady component of the circulation $\Omega_{0}$ ), set by the mean oceanic temperature gradients and surface winds, and a variable part $(\omega)$ controlled by variations in salinity gradients. The model parameters are defined as follows: $\epsilon$ is a coefficient setting the rate of change of ocean overturning induced by the buoyancy torque, $\lambda$ is a linear friction coefficient, $\beta$ is the haline contraction coefficient, $K$ is a linear damping coefficient, $F_{0}$ is the freshwater flux intensity, $S_{0}$ is a reference salinity, and $h$ is the loop depth or thickness. Numerical values are given in Table 1. Hence, the first equation describes the momentum balance, whereas the two other equations describe the evolution of the salinity gradients driven by advection, linear damping, and the surface salt flux. Further details about the model are found in Sévellec and Fedorov (2014, 2015B).

Table 1. Parameters of the Loop Model
$\begin{array}{ll}\text { h } & \mathbf{1 , 0 0 0} \mathrm{m}\end{array}$
depth of the level of no motion (i.e., the loop thickness)
$\Omega_{0} \quad-2.5 \times 10^{-2}$ $\mathrm{yr}^{-1}$




\section{Predictability of Decadal Atlantic Meridional Overturning Circulation Variations}

\begin{tabular}{|l|l|l|}
\hline$F_{0}$ & $1 \mathrm{~m} \mathrm{yr}^{-1}$ & freshwater flux intensity \\
\hline$S_{0}$ & $35 \mathrm{psu}$ & reference salinity \\
\hline$\lambda$ & $10^{-2} \mathrm{yr}^{-1}$ & friction coefficient \\
\hline$\epsilon$ & $0.35 \mathrm{yr}^{-2}$ & buoyancy torque coefficient \\
\hline$K$ & $10^{-4} \mathrm{yr}^{-1}$ & Laplacian eddy diffusion coefficient \\
\hline$\beta$ & $7 \times 10^{-4} \mathrm{psu}^{-1}$ & haline contraction coefficient \\
\hline
\end{tabular}

To study the evolution of this idealized model, we set up a large ensemble of 500 members slightly differing by their initial conditions following a multivariate normal distribution of standard deviation of $0.1 \mathrm{psu}$ and $10^{-3} \mathrm{yr}^{-1}$ for salinity gradients and overturning intensity, respectively. The evolution of the ensemble shows an overall divergence of the trajectories of the 500 members, typical of chaotic systems (Figure 3, left). However, unlike in the linear stochastic model, the evolution of the intermember standard deviation is not monotonic.
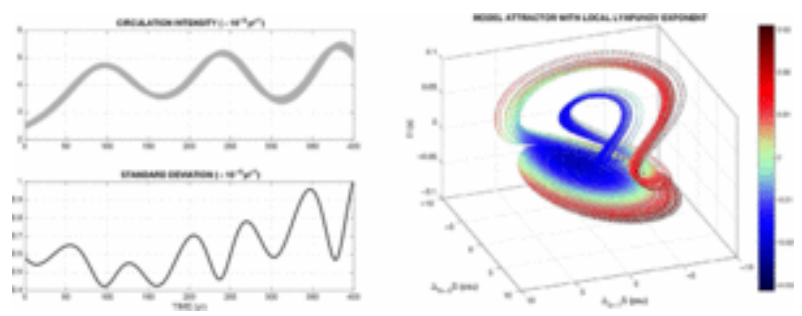

Click to view larger

Figure 3. Left, from top to bottom: Circulation intensity and standard deviation of the ensemble of 500 members for the deterministic idealized model. Right: One-year local Lyapunov exponent evaluated over the trajectory of the deterministic idealized model, following Equation (6). Color represents the growth of the small disturbances (i.e., positive and negative values suggest divergence and convergence of trajectory in phase space, respectively).
The nonmonotonic change in the intermember variance can be characterized by looking at the local Lyapunov exponent $(g)$ computed along the strange attractor of the loop model. For this purpose we compute the 1 year linear growth of normalized perturbations (i.e., the local Lyapunov exponent) along a long trajectory of the loop

model covering a large part of the system strange attractor.

$$
g(t)=\log \left[\frac{n(t+s)}{n(t)}\right] / s, \text { with } n(t)=\omega^{\prime 2}(t)+\left(\frac{\in \beta}{\lambda}\right)^{2}\left[S^{2}{ }_{B T}(t)+S^{2}{ }_{N S}(t)\right]
$$

(6)

and $X=\bar{X}+X^{\prime}$, where $X^{\prime}$ represents the anomaly, $\bar{X}$ the trajectory, and $X$ is any of the three variables: $\omega, S_{B T}$, and $S_{N S}$. $t$ is time and $s=1 \mathrm{yr}$. The evolution of the anomalies is given by the linearization of Equation (5) around the long trajectory. This diagnostic shows a regular structure in phase space (Figure 3, right). Positive/negative values suggest divergence/convergence of close trajectories. This explains how the evolution of the 


\section{Predictability of Decadal Atlantic Meridional Overturning Circulation Variations}

intermember standard deviation increases and decreases during its journey along divergent and convergent regions of the strange attractor, respectively (Figure 3, bottom left), and suggests that some regions of phase space, some states of the system, are more predictable than others depending on whether small disturbances between trajectories grow or decay.

\section{Discussion of Conceptual Approaches}

The two idealized models illustrate the two forms of chaos, stochastic and deterministic. The models fundamentally differ in their predictability. Whereas the stochastic framework suggests that the integration of the atmospheric stochastic forcing by the ocean induces a monotonic divergence of the trajectory (solely controlled by the oceanic adjustment timescale), the deterministic framework shows a more intricate behavior. Indeed, the latter shows that both divergence and convergence of trajectories can occur depending on the state of the system itself, despite an overall divergence of the trajectory on long timescales. This suggests that, unlike in the stochastic framework, in a deterministic framework, some states are more predictable than others, and some might even be fully predictable (the trajectories converge with a negligible uncertainty). This result is consistent with the analysis done by Slingo and Palmer (2011) using the chaotic model of Lorenz (1963).

Clearly, the two conceptual models are limited in their application to the real world, despite being extremely useful for illustrating different types of error growth (i.e., due to internal or external processes). Therefore, the discussion now shifts to more realistic studies that focus on assessing the predictability of the AMOC.

\section{Assessing the Predictability}

This section begins with description of modes of variability affecting the AMOC and the precursors of its changes, as well as processes contributing to the predictability of the AMOC. Then attention turns to a range of more theoretical studies determining the growth of small disturbances potentially affecting the AMOC and hence limiting its predictability. In the last part of the section, the focus is on describing the current pragmatic method, ensemble experiments using state-of-the-art climate models, to estimate AMOC predictability and on synthesizing the current knowledge gathered using this method.

\section{Contributing Factors}

Precursors of AMOC Changes 


\section{Predictability of Decadal Atlantic Meridional Overturning Circulation Variations}

One source of predictability of the AMOC is the existence of precursors of its changes. Precursors can be determined in a statistical sense or in a dynamical sense. For the former, the link between the precursor and AMOC changes is not formally identified, and it is only demonstrated that the occurrence of the two with a delay is robust in a statistical sense (there might not be a causal link between the precursor and AMOC changes). On the other hand, precursors might also be determined in a dynamical sense, suggesting that the precursors are a (proximate) cause of AMOC changes. In both cases, and because of nonlinearities of the system, there might exist a wide range of precursors depending on the initial magnitude of the AMOC (i.e., its position in phase space) and the nature of the change. Indeed, precursors of an AMOC decrease might be different if the AMOC is already low or high. There is a large body of work focused on determining precursors of AMOC changes. A few recent examples are discussed here.

Swingedouw et al. (2015) suggested that volcanic eruptions can play a significant role in the timing of AMOC variations with a 15-year delay. They suggested a succession of events that leads to a change in the AMOC. All of the events can be considered to be potential precursors of AMOC changes: East Greenland Current weakening with 12 to 15 years of delay, Labrador Sea buoyancy change with a delay of 10 to 12 years, subpolar convection with a delay of 7 to 9 years, for instance. This suggests a range of precursors and so of monitoring regions useful to anticipate AMOC changes. However, the links are robust only in a statistical sense (i.e., there is no demonstration that the precursors induce the AMOC changes through a physical mechanism).

Another recent study suggested that changes in deep buoyancy in the Labrador Sea are well correlated with AMOC changes 1 year later in a high-resolution coupled model (Robson et al., 2014B). The study also suggested that the link is consistent with observations. This implies that deep water in the Labrador Sea can be used to predict AMOC changes 1 year in advance. Despite suggesting a plausible physical explanation for this link, this study only robustly demonstrates a statistical link.

On the other hand, a body of work has characterized precursors in the causal sense. One tool that is particularly well fitted for this purpose is the "adjoint model," which allows the computation of the sensitivity of the AMOC to changes. Indeed, this method is by construction causal but is limited by its intrinsic assumption of linearity (i.e., precursors need to be small compared to the mean oceanic flow). In this context, Bugnion and Hill (2006) identified a range of surface oceanic precursors of AMOC changes, in an idealized flat-bottom rectangular-basin configuration of a general circulation model. The precursors include wind stress over the subtropical gyre on interannual timescales and surface heat flux gradient across the North Atlantic Current on decadal timescales. In a realistic configuration and focusing on surface precursors, Sévellec et al. (2008) and Sévellec and Fedorov (2015A) suggested that the most important precursor acts on a decadal timescale and corresponds to either a surface temperature or salinity perturbation in the subpolar region along the east coast of Greenland. Czeschel, Marshall, and Johnson (2010) confirmed this result and also identified the east coast of Europe as a potential temperature precursor to AMOC changes on decadal timescales.

Page 10 of 46

PRINTED FROM the OXFORD RESEARCH ENCYCLOPEDIA, CLIMATE SCIENCE (climatescience.oxfordre.com). (c) Oxford University Press USA, 2016. All Rights Reserved. Personal use only; commercial use is strictly prohibited (for details see Privacy Policy and Legal Notice). 


\section{Predictability of Decadal Atlantic Meridional Overturning Circulation Variations}

Heimbach et al. (2011) exhaustively characterized the different precursors of AMOC variations and their associated timescale (the reader is referred to this study for a full description of the precursors) and suggested the use of the adjoint method to design an efficient system for monitoring and anticipating AMOC variations.

Since the AMOC has been conjectured to be a multiple equilibria system (Marotzke \& Willebrand, 1991; Rahmstorf, 2000; Rahmstorf et al., 2005; Stommel, 1961), its predictability is also affected by our ability to anticipate an abrupt jump from its current equilibrium to another. Indeed, the changing climate, through freshening at high latitudes, might be able to push the AMOC beyond a threshold or a tipping point where it will be, and will remain, shut down (Barreiro et al., 2008; Dijkstra, 2007; Rahmstorf, 1995; Sévellec, Huck, \& Colin de Verdière, 2010). This is especially timely since direct and indirect measurements suggest that the AMOC is gradually weakening (Rahmstorf et al., 2015; Smeed et al., 2014), and it is anticipated to slow down during this century (Cheng, Chiang, \& Zhang, 2013). Hence, detection of early warning signals (Dakos et al., 2008; Lenton, 2011; Livina \& Lenton, 2007; Scheffer et al., 2009) of an AMOC abrupt shutdown has become an extensive and fruitful area of current research. The research aims to determine precursors through statistical (Cimatoribus et al., 2013) or dynamical (Sévellec \& Fedorov, 2014) approaches that assess the proximity of a dramatic AMOC event. In particular, it has been suggested that, whereas statistical early warning signals are weak (Cimatoribus et al., 2013), the ocean vertical stratification can be a good precursor of a dramatic collapse of the AMOC (Sévellec \& Fedorov, 2014). Although promising, so far these methods remain limited in their applications. Moreover, although the AMOC is anticipated to decrease, possibly dramatically, over the 21st century (Cheng et al., 2013), the risk of an abrupt collapse is perceived to be limited since it has only been experienced during glacial periods, rather than during interglacial periods like the present time (Bond et al., 1997, 1999; Dansgaard et al., 1993; Grootes \& Stuiver, 1997). Indeed, whereas the bistability of the AMOC during the last glacial period appears to be a plausible hypothesis confirmed by a wide range of studies (e.g., Colin de Verdière, 2007; Sakai \& Peltier, 1999), it remains an open question with conflicting evidence for the current climate state (Arzel, Colin de Verdière, \& England, 2010; Cimatoribus et al., 2012; Colin de Verdière \& te Raa, 2010; Huisman, den Toom, \& Dijkstra, 2010; Sévellec \& Fedorov, 2015B).

\section{Modes of Variability}

Beyond precursors, it has been suggested that internal modes of variability or harmonic oscillations of the ocean lead to an increase of predictability (Griffies \& Bryan, 1997). The rationale behind this result is that oscillations, even if damped, repeat themselves in time and so are a source of predictability. As discussed earlier and demonstrated by Chang et al. (2004), this is not the case if one measures the predictability through its predictive power, which only measures the relative increase in variance. However, other predictability metrics, such as autocorrelation coefficient, take into account the absolute change of the system, which is also dictated by modes of variability. In this context, robust internal modes of variability will increase the predictability by inducing changes 


\section{Predictability of Decadal Atlantic Meridional Overturning Circulation Variations}

with a well-defined timing if one initializes the modes accurately (i.e., by setting their phases correctly). Thus, the discussion now turns to state-of-the-art knowledge of modes of variability of the AMOC relevant on decadal timescales.

In the absence of direct observations of AMOC variability on decadal to multidecadal timescales (rapid observations being only a decade old; McCarthy et al., 2012; Srokosz \& Bryden, 2015), many studies concentrate on dominant climate modes in the Atlantic that may be linked to the AMOC. Climate modes are spatially coherent structures that describe large-scale variations of SST. The Atlantic multidecadal oscillation (AMO) is one of the climate modes particularly coherent in observations and is believed to reflect variations in the AMOC strength (Delworth \& Mann, 2000; Roberts et al., 2015; Schlesinger \& Ramankutty, 1994; Zhang, 2007). Despite the relatively short duration of the observational period and the limited accuracy of longer proxy records, the AMO is typically associated with periods between 50 and 70 years (Kushnir, 1994) and is possibly paced by volcanic eruptions (Oterrå et al., 2010; Swingedouw et al., 2015, 2017). In climate models, the AMO is associated with variations in the AMOC intensity on the order of $1 \mathrm{~Sv}$ (Knight et al., 2005). Potentially, the AMO can exert strong impacts on climate, affecting hurricane activity over the North Atlantic (Goldenberg et al., 2001) and precipitation over North America (Enfield et al., 2001; Sutton \& Hodson, 2005). Knight et al. (2006) linked the AMO and precipitation over Northeast Brazil, the African Sahel (see also Ward, 1998), and Northwest Europe. Msadek and Frankignoul (2009) showed global impacts of this variability, and indirectly of the AMOC, on SST and surface precipitation reaching the Indian Ocean and Central Asia. Sutton and Hodson (2003) linked the AMO and climate change over the North Atlantic.

Observational studies show the existence of not only 50- to 70-year variability, but also variability in the 20- to 30-year band (Figure 4 or Frankcombe et al., 2008). These two ranges of frequencies together contribute $54 \%$ of the annual AMO index and up to $85 \%$ of its decadal variations (Figure 4; see Appendix B for methodological details). The shorterperiod, interdecadal variability can be easily identified if one uses variations in temperature or sea level height (SLH) in latitudinal bands instead of using average SST. By analyzing SLH variations, Frankcombe and Dijkstra (2009) found a coherent westward propagating mode with a 20- to 30 -year period in both data and climate models. The authors hypothesized that the AMO might have a strong signature at 20 to 30 years in addition to the 50- to 70-year band more commonly associated with the AMO. Many coupled general circulation models (GCMs) display similar 20- to 30-year variability (Muir \& Fedorov, 2017)—CCSM3, for example (Danabasoglu, 2008). In addition, Latif et al. (2007) discussed the possibility of quasi-decadal variability in the Atlantic. 


\section{Predictability of Decadal Atlantic Meridional Overturning Circulation Variations}
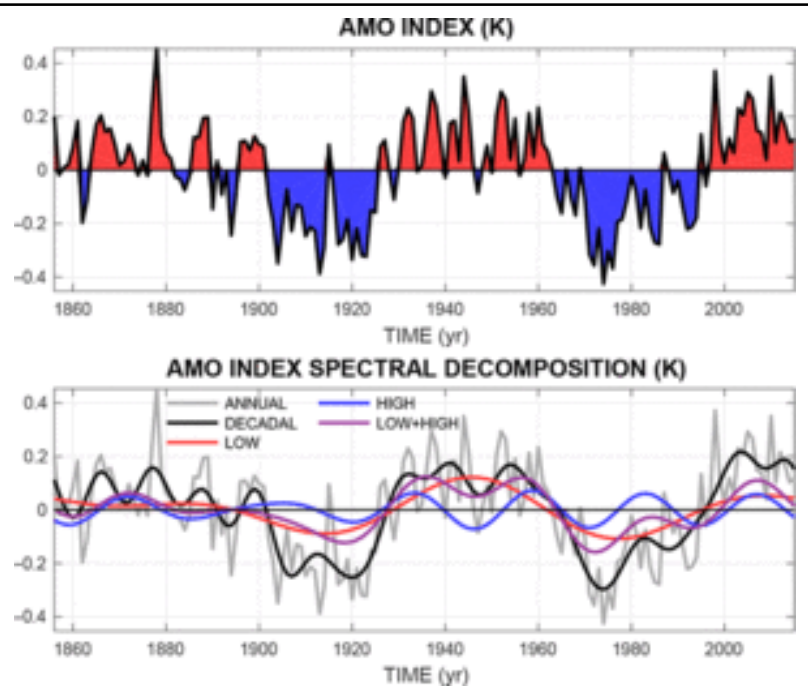

Click to view larger

Figure 4. AMO index from 1856 to 2015 following Enfield et al. (2001). Here AMO index is the annualmean SST anomaly averaged over the North Atlantic from $0^{\circ} \mathrm{N}$ to $70^{\circ} \mathrm{N}$. Top: Positive/warm and negative/ cold periods are highlighted in red and blue, respectively. Bottom: Spectral decomposition of the annual (gray line) and decadal (black line) AMO index in terms of its low-frequency component (50- to 70-year band, red line), its high-frequency component (20- to 30-year band, blue line), and the sum of the two components (purple line). Low and high frequencies contribute together to $54 \%$ and $85 \%$ of the annual and decadal AMO index variances (i.e., coefficient of determination of 0.54 and 0.85 ), respectively.
Despite these

clarifications, the physical mechanisms controlling the internal mode(s) in the North Atlantic, and even whether there are several modes or none at all, are still being strongly debated (IPCC, 2013). A review of different mechanisms in a hierarchy of models ranging from idealized to comprehensive was given by Yoshimori et al. (2010). Buckley and Marshall (2016) also discuss modes of variability affecting the AMOC. Hence, even if one focuses on the AMOC variability occurring on decadal to multidecadal timescales (i.e., excluding centennial or millennial, for instance), there are a

large number of oceanic processes and feedbacks that can potentially generate temporal variations in the North Atlantic (Dijkstra \& Ghil, 2005). A far from exhaustive list of general ideas for the mechanisms of decadal climate variability in the Atlantic would include:

- Large-scale basin modes (Ben Jelloul \& Huck, 2003, 2005; Cessi \& Paparella, 2001)

- Effects of the great salinity anomalies or similar anomalies (Belkin et al., 1998; Haak et al., 2003; Häkkinen, 1999; Zhang \& Vallis, 2006)

- Episodic deepening of the mixed layer in the areas of deep convection (Deshayes, Straneo, \& Spall, 2009; Spall, 2008)

- Baroclinic instability of large-scale Rossby waves propagating on the thermocline (Chen \& Ghil, 1995; Colin de Verdière \& Huck, 1999; Huck \& Vallis, 2001; Ortega et al., 2015; Sévellec \& Fedorov, 2013A; Sévellec \& Huck, 2015)

- Interaction between the ocean zonal and meridional circulations (Dijkstra et al., 2006; te Raa \& Dijkstra, 2002)

- The "intergyre" gyre effect (Marshall, Johnson, \& Goodman, 2001)

- Western boundary buoyancy forcing (Buckley et al., 2012). 


\section{Predictability of Decadal Atlantic Meridional Overturning Circulation Variations}

A number of studies focus specifically on the AMO-like variability (Latif, 1997; Yoshimori et al., 2010). Several particular mechanisms for the AMO have been proposed, from changes in the subtropical gyre (Cheng et al., 2004; Dong \& Sutton, 2005; D'Orgeville \& Peltier, 2009) to variability of the subpolar gyre that alters the heat budget of the Labrador Sea (Danabasoglu, 2008). Other studies focus more on the westwardpropagating mode with the 20- to 30-year period discussed earlier (Colin de Verdière \& Huck, 1999; Dijkstra et al., 2006; Huck \& Vallis, 2001; Huck et al., 1999; Ortega et al., 2015; te Raa \& Dijkstra, 2002; Sévellec \& Fedorov, 2013A; Sévellec \& Huck, 2015). The absence of a consensus on the mechanism driving AMOC variability on decadal timescales strongly limits our ability to predict its associated changes, since we do not know how to efficiently initialize it.

\section{Theoretical Investigations of Error Growth}

Despite the lack of understanding of modes of variability, predictability can still be assessed. Indeed, we can measure the increase in the system variance regardless of our knowledge of the physics or existence of internal modes, following the original idea of Lorenz (1965). This section describes a robust methodology to measure growth of perturbations (i.e., divergence of trajectories) and its application for assessing decadal predictability of the AMOC in ocean models.

Generalized stability analysis (GSA) has provided new tools for understanding stability and perturbation growth in geophysical fluid dynamics (Farrell \& Ioannou, 1996A, 1996B; Palmer, 1999). For the ocean circulation, GSA has been used in a number of applications, ranging from mesoscale eddies to the El Niño and Southern Oscillation and the thermohaline circulation (Moore et al., 2003; Tziperman \& Ioannou, 2002). Unlike classical stability analysis, which treats asymptotic stability, GSA considers perturbation growth over a finite time and allows for transient growth in a time-varying system. Consequently, the method can consider the sensitivity of changing climate on different timescales, making it relevant to predictability (Palmer, 1999). However, it is not yet a method that is widely spread in the oceanographic and climatic communities and few groups use this method in realistic settings.

Next, the mathematical principle behind GSA is described, and then the discussion turns to its application in the context of the AMOC, which has yielded new and robust insights into its predictability.

\section{Method}

The prognostic equations of a fully nonlinear model can be written as a general nonautonomous (i.e., changing with time) dynamical system:

$$
\left.d_{t}|U\rangle=N(U\rangle, t\right)
$$




\section{Predictability of Decadal Atlantic Meridional Overturning Circulation Variations}

where $\mathrm{N}$ is a time-dependent nonlinear operator, $|\mathrm{U}\rangle$ is a state vector consisting of all prognostic variables, and $t$ is time. For an ocean GCM, the state vector is comprised of the three-dimensional fields of temperature, salinity, and meridional and zonal velocity, together with the two-dimensional field of barotropic streamfunction or sea-surface height. Since we study a finite-dimensional vector space, we can also define a dual vector $\langle U|$ through the Euclidean scalar product $\langle U \mid U\rangle$.

We decompose the state vector as $|U\rangle=|\bar{U}\rangle+|u\rangle$, where $|\bar{U}\rangle$ is the nonlinear trajectory (i.e., the background state) and $|u\rangle$ is a perturbation. The temporal evolution of the perturbation follows a linear equation:

$$
\left.\left.d_{t} u\right\rangle=A(t) u\right\rangle, A(t)=\left.\frac{\partial N}{\partial|u\rangle}\right|_{U\rangle}
$$

(8)

where $\mathrm{A}(\mathrm{t})$ is a Jacobian matrix (a function of the trajectory $|\overline{\mathrm{U}}\rangle$ ). We also defined an adjoint to the Jacobian matrix as $\langle a|\mathrm{~A}| b\rangle=\left\langle b\left|\mathrm{~A}^{\dagger}\right| a\right\rangle$, where $|a\rangle$ and $|b\rangle$ are two anomalous state vectors, and + denotes the adjoint defined through the Euclidian scalar product $\langle a \mid b\rangle=\langle b \mid a\rangle$.

We can integrate Equation (8) to obtain an explicit expression for the perturbation as a function of time (Farrell \& Ioannou, 1996B):

$$
\left|u\left(t_{2}\right)\right\rangle=\mathbf{M}\left(t_{2}, t_{1}\right)\left|u\left(t_{1}\right)\right\rangle,
$$

(9)

where $\mathbf{M}\left(t_{2}, t_{1}\right)$ is called the propagator of the linearized dynamics from time $t_{1}$ to time $t_{2}$. If the propagator (or the Jacobian matrix) does not commute with its adjoint, $\mathbf{M}^{\dagger}\left(t_{2}, t_{1}\right) \mathbf{M}\left(t_{2}, t_{1}\right) \neq \mathbf{M}\left(t_{2}, t_{1}\right) \mathbf{M}^{\dagger}\left(t_{2}, t_{1}\right)$, the dynamics are nonnormal and more inclined to variability than a normal system (Ioannou, 1995).

We also define a norm for the state vectors: $\langle u|\mathbf{S}| u\rangle$. Finally, to evaluate the optimal growth of small initial disturbances, we define the Lagrangian function as:

$$
\left.\mathrm{L}\left(u\left(t_{i}\right)\right\rangle, \gamma\right)=\left\langle u\left(t_{m}\right) \mathbf{S}\left\langle u\left(t_{m}\right)\right\rangle-\gamma\left(\left\langle u\left(t_{i}\right)|\mathrm{S}| u\left(t_{i}\right)\right\rangle-\epsilon^{2}\right),\right.
$$

(10)

where $t_{i}$ is the initial time (when the optimal initial perturbation is applied), $t_{m}$ is the maximization time (when the norm reaches its maximum), and $\gamma$ is a Lagrange multiplier. (Note that, in general, the norm applied in the first and second terms of the right-hand side can be different.) $\epsilon$ is a parameter associated with the normalization constraint:

$$
\left\langle u\left(t_{i}\right)|\mathbf{S}| u\left(t_{i}\right)\right\rangle=\epsilon^{2}
$$

That is, $\epsilon$ measures the magnitude of the initial perturbation. Thus, the goal here is to maximize the norm subject to this normalization constraint. Hence, if the norms applied 


\section{Predictability of Decadal Atlantic Meridional Overturning Circulation Variations}

in the first and second terms of the right-hand side of Equation (10) are equivalent, the optimization identifies the maximum growth of the perturbation measured through this norm. This growth would be given by $\gamma$.

From Equation (10) and the optimization condition $d \mathrm{~L}=0$ the optimal initial perturbations are computed as:

$$
\left.\mathbf{M}^{\dagger}\left(t_{m}, t_{i}\right) \mathbf{S M}\left(t_{m}, t_{j}\right) u_{\left\{t_{i j} t_{m}\right\}}^{\text {opt }}\left(t_{j}\right)\right\rangle=\gamma \mathbf{S}\left|u_{\left\{t_{i} t_{m}\right\}}^{\text {opt }}\left(t_{i}\right)\right\rangle
$$

(12)

This expression gives the solution of the optimization problem, through the generalized eigenvalue problem of $\mathbf{M}^{\dagger}\left(t_{m}, t_{i}\right) \mathbf{S M}\left(t_{m}, t_{i}\right)$, also called singular value decomposition (SVD; Farrell \& Ioannou, 1996B), with the eigenvectors $\left|u_{\left\{t_{i} t_{m}\right\}}^{\text {opt }}\left(t_{j}\right)\right\rangle$ and eigenvalue $\gamma$. It depends both on the initial time $t_{i}$ and the maximization time $t_{m}$, so that an eigenvalue problem must be solved for each studied delay.

\section{Application}

This method has been applied in the context of the AMOC by Tziperman and Ioannou (2002) in an idealized box-model (Stommel, 1961). They showed, in the context of the AMOC, that small disturbances are able to grow on transient timescales, despite the system's being asymptotically stable. This study has been extended using more complex models by Zanna and Tziperman $(2005,2008)$ and Zanna et al. $(2011)$, generalizing the transient growth behavior up to primitive equation models. However, the model configuration remains idealized (rectangular basin with flat bottom). Indeed, solving an eigenvalue problem, such as Equation (12), is numerically costly and the computation of SVDs has not been performed in the most realistic state-of-the-art models yet.

Two alternative approaches have been suggested to overcome the numerical cost of generalized stability analysis and to allow the computation of transient growth in state-ofthe-art realistic model settings. The first alternative was suggested by Sévellec et al. $(2007,2009)$. The authors demonstrated that the use of a linear cost function-the first term on the right-hand side of Equation (10)-instead of a norm to measure the transient change leads to an explicit solution (versus an eigenvalue problem). This is a lot more efficient to compute and so also tractable on a range of transient delays in realistic configurations (Sévellec et al., 2008). This method is a synthesis of GSA and adjoint sensitivity analysis (Czeschel et al., 2010; Marotzke et al., 1999) and suggests an optimal transient growth of the AMOC on decadal timescales from a surface perturbation (Sévellec \& Fedorov, 2015A). Despite making progress toward realism, this method is limited to coarse resolution forced ocean models. Indeed, given its linear framework, either atmospheric or oceanic small-scale instabilities will continuously grow and will eventually dominate the model response.

Another alternative method has been suggested by Tziperman et al. (2008). The authors used a reduced-space representation of a coupled ocean-atmosphere model, based on a finite sum of empirical orthogonal functions (EOFs) for the 3-dimensional temperature 


\section{Predictability of Decadal Atlantic Meridional Overturning Circulation Variations}

and salinity fields. This method has the advantage of representing the tangent linear and adjoint models without explicitly using them. Hence it allows the computation of SVDs in coupled (and potentially high-resolution) models. The authors showed that the optimal transient growth occurred between 5 and 10 years, providing an estimated time for the AMOC predictability in the North Atlantic. Following a similar approach, Hawkins and Sutton (2009A, 2011) suggested an optimal transient growth at 35 years. It is interesting to note that these studies have shown the importance of either convection sites or deep oceanic regions, consistently with Sévellec and Fedorov (2015A, 2017), who suggested enhanced sensitivity of the AMOC to deep density anomalies because of their longer residence time (Sévellec \& Fedorov, 2013B).

Following the same approach, and taking advantage of the fact that it does not require the explicit linear and adjoint models, Zanna (2012) applied the same method using SST reanalysis. The author suggested the existence of an optimal transient growth of surface average temperature anomalies between 3 and 4 years, possibly limiting the predictability of this metric. Overall, all the approaches have shown promising results to assess the climate predictability by allowing computation in state-of-the-art climate models and even the direct use of observations, albeit only well-monitored ones (i.e., SST). However, the methods still have shortcomings. For example, the reduction to a finite sum of EOFs has been suggested to be far from ideal for representing the system non-normality (Farrell \& Ioannou, 2001), the latter being at the core of transient growth. Also, this approach, like the others discussed so far, remains in a linear framework, despite the system's being potentially strongly nonlinear. There are methods that fully deal with nonlinearities, but, as with SVDs, they are still restricted to relatively idealized models (Mu et al., 2004; $\mathrm{Zu}$ et al., 2016).

\section{Ensemble Experiments}

As already mentioned, an alternative approach exists that is not bounded by the technical difficulties of the theoretical investigations. This more pragmatic approach is often referred to as ensemble experiments (Hurrell et al., 2006; Meehl et al., 2009, 2015). It consists of setting up a large number of numerical simulations differing slightly in their initial conditions to represent the inherent state-estimation uncertainty (Boer, 2000, 2004, 2011). These studies are often done in a "perfect model approach," assuming the initial condition is the only uncertainty (e.g., there is no uncertainty linked to model error and/ or to a forcing scenario). This allows focusing on the role of initial condition uncertainty. The predictability is estimated by statistically diagnosing the ensemble spread of the numerical simulations. The rationale behind the method is that, by sampling effectively the initial condition uncertainty, we will have a good representation of the evolution of the probability density distribution. The spreading of the latter in phase space represents the growth of the uncertainty, and so is a measure of the system predictability. 


\section{Predictability of Decadal Atlantic Meridional Overturning Circulation Variations}

Unlike the theoretical methods previously described, the pragmatic method is relatively easy to apply and has allowed the study of climate predictability since the 1990s (Griffies \& Bryan, 1997). However, it still faces an important challenge, which is the way to set the initial conditions or the ensemble design. Several techniques exist to sample as accurately as possible the initial condition uncertainty, from adding random perturbations to the atmospheric state (Persechino et al., 2013) to switching day-lagged atmospheric states (Griffies \& Bryan, 1997), for instance. However, these methods mostly concentrate on the atmospheric state (with little or no consideration of the initial condition uncertainty in the oceanic state). In this context, Du et al. (2012) and Germe et al. (2017) have attempted to rationalize the role of the oceanic uncertainty in the ensemble design. Du et al. (2012) suggested that oceanic uncertainty modifies the decadal climate predictability, and Germe et al. (2017) also suggested a direct stimulation of atmospheric divergence by oceanic perturbation even though it was located in the deep ocean.

In an early attempt to characterize the AMOC predictability, Griffies and Bryan (1997) suggested that the main mode of variability for the SST is predictable for 5 to 7 years. They noted that this value can be reduced in the absence of periodic decadal oscillations in the system. Later, Collins and Sinha (2003) suggested the predictability of the AMOC for one to two decades, or even up to 50 years under certain conditions. This was confirmed by Pohlmann et al. (2004), who suggested predictability on multidecadal timescales for SST and SAT in the North Atlantic and Nordic Seas. However, Pohlmann et al. (2004) showed the predictability of SAT over land is limited to maritime-influenced regions (i.e., European coastal regions), while Collins and Sinha (2003) suggested that AMOC predictability leads to predictability of Western Europe SAT variations. Generalizing these studies through a multimodel-ensemble study, Collins et al. (2006) showed that the AMOC and SAT in the North Atlantic are predictable on interannual to decadal timescales. Building on this, Keenlyside et al. (2008) suggested that this potential predictability, especially in the North Atlantic, can be converted to routine decadal climate prediction with a good initialization of the ocean state. More recently, Msadek et al. (2010) suggested AMOC predictability up to 2 decades ahead and similar predictability for upper ocean heat content variations. These results were questioned by Teng, Branstator, and Meehl (2011), who suggested, in climate change ensemble experiments, that the AMOC might only be predictable for a decade before the long secular forcing dominates its behavior. In the same context, Teng, Branstator, and Meehl (2011) showed that the upper-500-m oceanic temperature in the North Atlantic might be predictable by several more years. Following the idea of Keenlyside et al. (2008), Swingedouw et al. (2013) suggested that prediction can be improved by an accurate constraint of the SST toward observations. In particular, their study showed a significant increase in predictive ability of the 2-m air temperature regions bordering the North Atlantic, and a good AMOC predictive ability for up to 4 years. This contrasts with the results of Persechino et al. (2013): using exactly the same model, they showed that the AMOC has an average predictability of 8 years, whereas surface temperature in the North Atlantic can have predictive ability up to 2 decades. 


\section{Predictability of Decadal Atlantic Meridional Overturning Circulation Variations}

Despite the body of evidence suggesting the potential decadal predictability of climatically relevant large-scale features (Latif et al., 2006), there is little quantitative agreement among studies. Thus, after decade-long progress by the scientific community, going beyond qualitative assessment remains a timely scientific objective. One possible reason for this is the shortcoming of current ensemble experiment design. Due to computational limitation, most ensembles are designed with 10 members at best. This might be enough for a qualitative assessment of the predictability but not for a quantitative one. Indeed, in the idealized model described in section STOCHASTIC FRAMEWORK, the qualitative aspect of the error growth is well captured with a relatively low number of members (i.e., 8-10 members). On the other hand, several tens, if not more than a hundred, members are needed for an accurate quantitative estimation of predictability (Figure 5). Since this result is obtained with a linear 1 degree-of-freedom system, it is expected to be more dramatic in the context of climate models, which have a significantly higher number of degrees of freedom (e.g., there are more than 2 million semi-independent variables just for the ocean-only model, NEMO-ORCA2; Madec, 2008). Hence, it appears that quantitative assessments might be reached in the near future by increases in computational power or, alternatively, through a breakthrough in the way ensembles are designed (Baehr \& Piontek, 2014; Ramanova \& Hense, 2015).
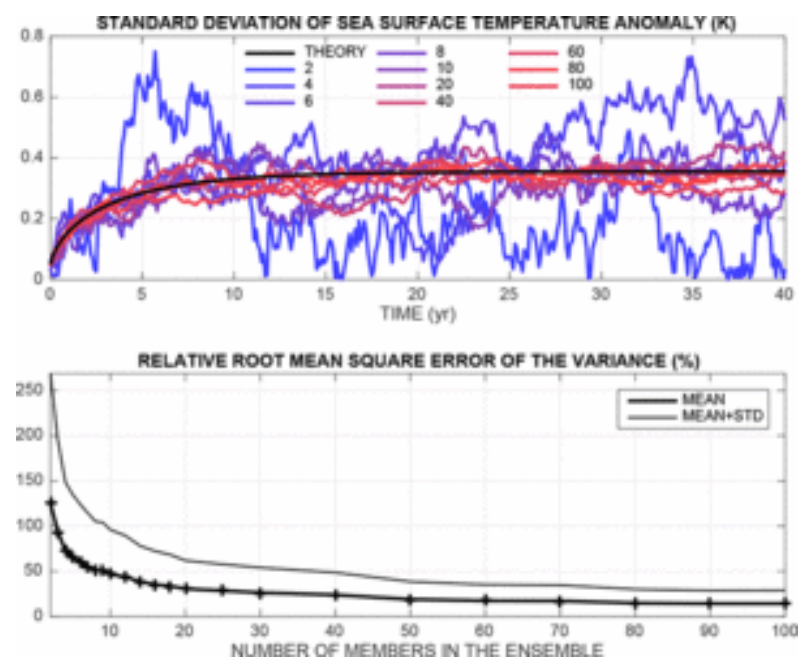

Click to view larger

Figure 5. Top: Evolution of the standard deviation of SST anomaly for the stochastic idealized model, using different sizes of ensemble (the number of members are indicated in the key to colored lines) together with the theoretical results from Equation (2). Bottom: Convergence of the variance to the theoretical value as a function of the number of members in the ensemble. The convergence is measured by the root mean square distance between ensemble and theoretical value divided by the timemean of the theoretical variance. To obtain accurate statistics, each ensemble has been reproduced 100 times for ensembles with $\leq 20$ members and 20 times for ensembles with $>20$ members. The results are displayed in term of the average and average

\footnotetext{
Page 19 of 46
}

PRINTED FROM the OXFORD RESEARCH ENCYCLOPEDIA, CLIMATE SCIENCE (climatescience.oxfordre.com). (c) Oxford University Press USA, 2016. All Rights Reserved. Personal use only; commercial use is strictly prohibited (for details see Privacy Policy and Legal Notice). 


\section{State of the Art and Current Challenges of Interannual to Decadal Prediction}

\section{Decadal Prediction Systems: Hindcasts and Forecasts}

Decadal prediction, as opposed to predictability, poses its own set of problems, but it carries the potential to provide societally relevant and useful forecasts. The first decadal prediction studies were published in the early 2000s (Keenlyside et al., 2008; Pohlmann et al., 2009; Smith et al., 2007), following pioneering perfect model predictability studies, such as those by Griffies and Bryan (1997), Collins and Sinha (2003), and Collins et al. (2006). The new challenges were initialization, radiative forcing, model bias, drift from initialization, validation and skill assessment, computational expense, the latter limiting both model complexity and resolution, and ensemble size. The main effort has focused on global mean near surface temperature, but more recently predictions are beginning to include regional temperature and other variables, such as rainfall and winds, and ocean circulation, such as the AMOC. 


\section{Predictability of Decadal Atlantic Meridional Overturning Circulation Variations}

\section{Initialization and Data Assimilation}

Most effort has concentrated on initialization of the ocean component of the climate system, since it has the largest heat capacity, and the bulk of the memory of the system resides there. Recently, there has been research on the importance of initializing other components of the system, including land and sea ice.

For the ocean, two main methods are available: full field and anomaly initialization. In the former, an estimate of the full initial temperature and salinity fields (and in some cases, other state variables, such as sea-surface height and zonal and meridional velocities) is obtained on the model grid (methods described in the next paragraph) and is used as the initial condition. In the latter case, anomalies with respect to an observed climatology are prepared on the model grid and added to a model climatology. Although both methods have their proponents, the most comprehensive study to date comparing the two methods concludes that there is little to choose from in terms of decadal prediction skill (Hazeleger et al., 2013).

The problem of obtaining observation-based data on the model grid is common to both approaches, and a variety of methods are used. There are two broad choices: one is to use products based only on observations using statistical methods (e.g., optimal interpolation) with no dynamical model (such as an ocean GCM), although a model may be used to estimate spatial covariances, which are inputs to the statistical model (Smith et al., 2007). The second and by far more common approach is to use a dynamical model to assimilate a subset of available observations in order to provide an estimate of the ocean state at the desired starting point of the forecast. The assimilation methods vary from simple nudging toward observed SST fields (Keenlyside et al., 2008), to nudging to three-dimensional temperature and salinity (Smith et al., 2007, 2010), to more complex data assimilation (DA) methods, such as three-dimensional (Balmaseda, Trenberth, \& Källén, 2013) and four-dimensional (Mochizuki et al., 2016; Wunsch \& Heimbach, 2007) variational data assimilation. Another approach is to avoid altogether the need for assimilation of ocean data and instead to simply specify surface fluxes (with strong relaxation to observed SST) or to specify near surface meteorological variables, such as winds, and to allow the model fluxes to vary based on bulk formulae. Doblas-Reyes et al. (2011) and Matei et al. (2012) demonstrated cases where assimilation of subsurface observations has no significant effect on decadal prediction skill. In contrast, Dunstone and Smith (2010) and Counillon et al. (2014) suggested that, for some aspects (such as the AMOC), use of subsurface ocean observations is beneficial.

The initial atmosphere state has historically been considered less important for decadal forecasting (e.g., Dunstone \& Smith, 2010, show that the atmospheric state has little impact beyond the first year in the DePreSys forecast system). Nonetheless, many forecast systems are initialized with atmospheric observations, such as atmospheric reanalyses. For example, Smith et al. (2007) used ECMWF reanalyses (Anderson et al., 


\section{Predictability of Decadal Atlantic Meridional Overturning Circulation Variations}

2007). In decadal forecasting, the main emphasis involving atmosphere initial conditions is now on coupled ocean-atmosphere data assimilation (see below).

Sea ice initialization is still being developed. For example, Guemas et al. (2014) found a modest increase in forecast skill for Arctic sea ice extent and surface air temperature using the EC-Earth climate model when initializing with a sea ice field, from a model that was strongly constrained to be consistent with observed atmosphere and ocean observations, compared to using sea-ice from a free running (no data assimilation) forced ocean-ice model hindcast, and thus weakly constrained and less realistic. However, the Antarctic sea ice extent was slightly less skillfully predicted and there was very little effect on the global surface air temperature forecast skill.

Coupled ocean-atmosphere data assimilation methods are also gaining ground and continue to be an active area of research. To date, proof-of-concept studies have been performed using intermediate-complexity coupled models. Data assimilation can be weakly coupled, where the coupled model is used to provide a background state, or it can be strongly coupled, where covariances between atmosphere and ocean variables are used so that atmospheric observations can directly affect the ocean state and vice versa. A number of studies indicate that strongly coupled data assimilation can improve the mean state of both atmosphere and ocean over the weakly coupled case, notably that of Sluka, Penny, Kalnay, and Miyoshi (2016), where only atmosphere observations are assimilated and result in an improved ocean state, with subsequent feedback to further improve the atmospheric state. Tardif, Hakim, and Snyder (2014) investigated the value of coupled DA for accurate simulation of the AMOC. However coupled DA appears particularly useful when few ocean observations are available, hinting that more comprehensive observations of the ocean (e.g., below the current depth range of $0-2,000$ $\mathrm{m}$ of the Argo fleet) may be as, or more, important for decadal forecasting than coupled DA techniques. Simpler procedures, such as that of Thoma et al. (2015), where the coupled system is spun up using observed windstresses to drive the ocean, are still being tested. The Thoma et al. (2015) scheme shows some promise in the Pacific sector, but less in the Atlantic.

Land is usually not directly initialized, but initialization of ocean and atmosphere implicitly initializes land: for example, Smith et al. (2010) applied nudging to observations (reanalysis) in order to initialize the atmospheric state, which results in the modification of the land state to achieve energy and moisture balance with the atmosphere. Explicit initialization is becoming more feasible (e.g., using satellite observations of soil moisture), but at the time of writing has not been incorporated into operational decadal forecast systems.

For decadal forecasts, generation of ensemble members is still usually ad hoc (e.g., using a number of nearby initial atmospheric start dates from a control simulation, or random perturbation to the SST field). This ad hoc approach carries a risk that the forecast ensemble will underestimate the true width of the climate variable probability density at any given lead time. Methods like those of Karspeck et al. (2013) and Baehr and Piontek 


\section{Predictability of Decadal Atlantic Meridional Overturning Circulation Variations}

(2014) attempted to circumvent this risk by using more advanced techniques, such as the ensemble Kalman filter and breeding methods, respectively. Similar arguments apply to the ocean, and methods like GSA (Section THEORETICAL INVESTIGATIONS OF ERROR GROWTH) may be applied to maximize the spread in forecasts at a given lead time. However, such methods might be counterproductive in some cases, since many forecast systems already overestimate the variability (Eade et al., 2014; see also VALIDATION AND SKILL for further details).

\section{Radiative Forcing}

For hindcasts, the usual treatment of radiative forcing has been to specify atmospheric concentrations of anthropogenic and volcanic aerosols, anthropogenic $\mathrm{CO}_{2}$ and other greenhouse gases, and variations of incident solar radiation at the top of the atmosphere from the best available observations. Uncertainty in estimates of these quantities may influence the accuracy of the initial conditions as they input to the assimilation process and will also directly influence hindcasts. Particularly for aerosols, some significant uncertainty remains over the actual evolution of the atmospheric aerosol burden over the period of historical observations. This uncertainty is being addressed, for example, through ongoing research into the chemical and physical processes responsible for aerosol concentration (e.g., cloud microphysics). Revised estimates of aerosol historical evolution are likely to be available in the next few years (Mills et al., 2016). However, even if the correct aerosol and gases were present, there would still be uncertainty in how the climate system responds to them (especially clouds). Mitigating this is the fact that the observations used in initializing the models are affected by the history of forcing and have the correct response.

Major volcanic eruptions cannot at present be predicted in advance and are neglected for decadal forecasts. However, should a major eruption occur, a forecast could soon be run to get some idea of the impacts over the next few years. On longer timescales, the probability of major volcanic eruptions, such as Mt. Pinatubo in 1991, can be fitted to high accuracy with a Poisson distribution (Roscoe, 2001). For decadal timescales, small to moderate eruptions have a significant cumulative effect (Timmreck et al., 2016), and ongoing work suggests these moderate eruptions have a similar statistical distribution to the major eruptions (A. Schmidt, unpublished data). The distributions could potentially be incorporated into next-generation decadal forecast systems.

Although there have been numerous studies, and the general consensus is that the AMOC response consists of an increase in the first decade following eruption, followed by a decline, a wide range of behavior and mechanisms is found, with potential dependence on the prevailing climate state at the time of the eruption (Mignot et al., 2011), seasonality, and subsequent and previous eruptions (Swingedouw et al., 2015). Different models favor different mechanisms, ranging from the direct effect of high-latitude cooling (Jones et al., 2005) to indirect effects resulting from modifications to the hydrological cycle (precipitation, evaporation, and runoff; Iwi et al., 2012), to a combination of both effects 


\section{Predictability of Decadal Atlantic Meridional Overturning Circulation Variations}

(Pausata et al., 2015), and to sea ice changes (Swingedouw et al., 2015), depending also on the strength of the eruption. Solar forcing is generally related to the observed changes in radiation following the 11-year solar cycle (Willson, 2014), and for forecasts it is set to be identical to the previous 11-year cycle. Before the launch of satellite radiometers (late 1970s), no direct measurements of solar irradiance at the top of the atmosphere were available and the irradiance is reconstructed from sunspot observations.

Greenhouse gas concentration variations are likely to have a minor effect over a given decadal forecast period; therefore, the exact choice of future scenario is not very important on such timescales (Figure 1 and Hawkins \& Sutton, 2009B). Nonetheless, even if the predictability of the AMOC arising from initialization may fall away on the timescales of years to decades, considerable (and nontrivial) predictability arises from the greenhouse gas forcing, especially on multidecadal timescales.

\section{Model Bias, Drift, and Bias Correction}

The key point here is that models are an imperfect representation of the real world. Hence, the model attractor is different from the real-world attractor. Thus, when initializing with observations, models tend to drift to the preferred state of the model. This is typically corrected with a lead-dependent bias correction constructed from the mean difference between a large number of hindcasts and the observations at a given lead time. Figure 6 illustrates the point with a postulated attractor corresponding to "reality" and another corresponding to the model (both based on the model of Sévellec and Fedorov, 2014, shown in Figure 3). In the case illustrated in the top left panel of Figure 6, the colored trajectories represent "reality," while the gray contours represent a "model" attractor, derived from the real one via a strain transformation. Initial conditions derived from observations (points A and B) are displaced with respect to the model attractor and the model quickly evolves to a state on the model attractor (points $\mathrm{A}^{\prime}$ and $\mathrm{B}^{\prime}$ respectively). Depending on the nature of the attractor, the drift may be to the "correct" state (i.e., an analogue of the real initial state B'), or it may evolve to an "incorrect state" (A'). If the drift results in the model's moving to a state analogous to the initial observations, and the model attractor is similar to reality, we may obtain a skillful forecast if the drift is subtracted from the model predictions and an estimate of the drift is given by the mean displacement of the model predictions with respect to the observations. In the case illustrated, an average mean bias correction would work quite well for the initial state B, but less well for initial state A. Problems with a simple bias correction occur if the model attractor is translated (lower left panel), rotated (top right), or distorted (strain transformation already discussed) compared to the real attractor. In the general case, the model attractor will be related to the real one by some combination of these three transformations. 


\section{Predictability of Decadal Atlantic Meridional Overturning Circulation Variations}

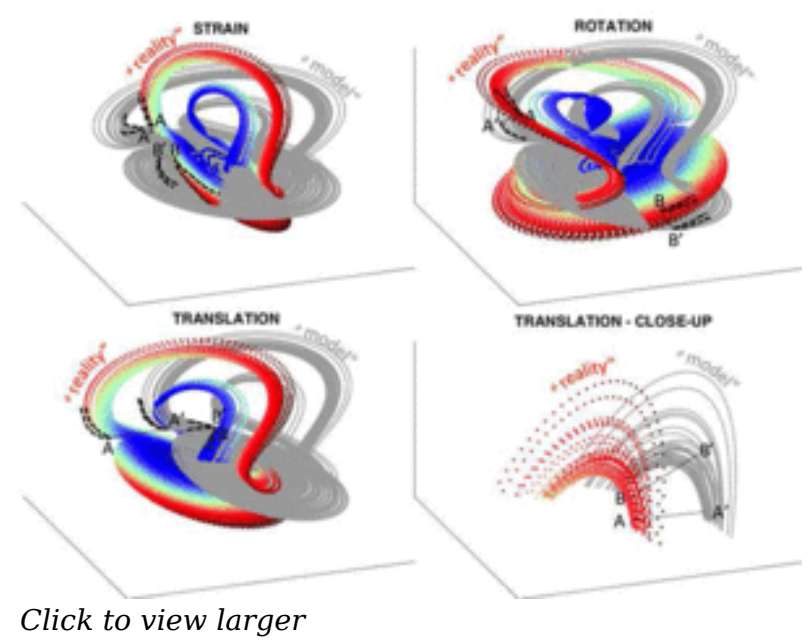

Figure 6. Illustration of the effects of model bias on decadal prediction skill and error growth. Top, right: The attractor for the deterministic chaos model from Figure 3 is shown in color, representing the realworld attractor. Gray lines trace the attractor of a postulated biased model, related to the real-world attractor by a strain transformation. A decadal prediction system is initialized at two points on the real-world attractor (points A and B). Dashed lines from these points indicate the envelope of the trajectories from points A and B if the model were unbiased. Thin black lines indicate rapid drift of the model state from the initialization (points $A$ and $B$ ) to points on the model attractor ( $\mathrm{A}^{\prime}$ and $\left.\mathrm{B}^{\prime}\right)$. The biased model then predicts a spread of trajectories from these points, represented by the dashed lines originating from points $\mathrm{A}^{\prime}$ and $\mathrm{B}^{\prime}$. Similar diagrams represent the effect of the biased model attractor related to the real-world attractor by a rotation (top right) and a translation (bottom left). The final panel (bottom right) shows an enlargement of part of the bottom left panel and indicates that, even for a simple translation, the direction of the drift from initialization to the model attractor may vary for different initialization points.
Figure 6 illustrates that the model bias may vary, not only with lead time, but with model state (e.g., whether or not the model is in an El Niño state; Choudhury et al., 2016) and whether the local model trend is different from the true trend (see Meehl, Teng, \& Arblaster, 2014). For decadal forecasting in particular, there is now strong evidence that a large number of start dates (at least yearly) is at least as important as increasing ensemble size and that a more sophisticated bias correction is beneficial. A further point to note (bottom right panel) is that even in the relatively simple case of a constant translation of the model attractor relative to reality, the forecast bias can vary with model state, as the rate and direction of the initial drift will depend on

the local topology of the attractor (i.e., line $\mathrm{AA}^{\prime}$ is not parallel to $\mathrm{BB}^{\prime}$ ).

A way forward is to address the biases of individual models (e.g., Huang et al., 2015) in order to bring their attractors closer to the real-world attractor, inferred, as far as possible, from observations. This process of model improvement is ongoing but often incremental (e.g., Knight et al., 2014); hence, research on more accurate bias adjustment continues (Narapusetty, Stan, \& Kumar, 2014) and detailed analysis of drift dynamics is required to focus model development efforts where they will have the most effect in reducing drift (Sanchez-Gomez et al., 2016).

\section{Validation and Skill}




\section{Predictability of Decadal Atlantic Meridional Overturning Circulation Variations}

Validation methods for decadal forecasts have drawn heavily from the experiences of the numerical weather prediction and seasonal forecasting communities, although relatively simple measures of skill, such as anomaly correlation coefficient (ACC) and root mean square error (RMSE), remain in common use (Collins, 2002). A key issue of debate is the relationship between potential predictability and actual skill (Boer, Kharin, \& Merryfield, 2013), because the difference between the two measures is thought by many to indicate the possibility of improving forecast systems (e.g., by modifying the observing system, initialization/assimilation procedures, or model biases; Kumar, Peng, \& Chen, 2014). The implications of comparing an ensemble mean variable from a forecast system with the single realization obtained from observations have yet to be fully explored but are understood in terms of a predictable component ("signal"), common to all ensemble members in a forecast, and an unpredictable component, which varies randomly between ensemble members ("noise"). Eade et al. (2014) made a key assumption that a correlation between observational time series and an ensemble mean time series obtained from a forecast is indicative of the real-world predictable component for that variable, allowing an assessment of the relative sizes of the predictable and unpredictable components in models versus observations. This gives a useful procedure for identifying regions where model signal-to-noise ratio is either too high or too low and is likely to result in deeper understanding of the processes giving rise to predictability in different regions, as well as the fidelity of model representations of these processes. However, a number of subtle issues still need to be explored. For example, a problematic element of the analysis done by Eade et al. (2014) is that the predictable element of the real world must be estimated from the model prediction system itself, and different systems may thus give very different estimates. Set against this is evidence that many forecast systems overestimate the variability (e.g., particularly in the North Atlantic for predictions of the SAT and NAO; see Eade et al., 2014). In view of this, maximizing the ensemble spread may in fact be problematic; rather, it may be desirable to apply postprocessing adjustments to bring the ensemble spread in line with expectation based on observations.

On the other hand, skill scores have been calculated for decadal hindcasts produced by operational decadal forecasting systems. Simple measures, such as the RMSE and ACC, are sufficient to indicate whether initialization results in enhanced skill (beyond persistence) over uninitialized forecasts. It has been widely noted that the North Atlantic subpolar gyre region displays enhanced skill in decadal forecasts of SST and upper ocean heat content compared to most other regions of the globe (van Oldenborgh et al., 2012; Pohlmann et al., 2009; Robson et al., 2017). Taking the Pohlmann et al. (2009) results, the North Atlantic ACC for SST averaged over $50^{\circ} \mathrm{W}$ to $10^{\circ} \mathrm{W}$ and $0^{\circ} \mathrm{N}$ to $60^{\circ} \mathrm{N}$ is on the order 0.7 for pentadal time scales, clearly superior to persistence $(0.2)$ or a trend forecast $(0.0)$. Detailed process studies (Robson et al., 2012A, 2012B, 2014A) indicate that decadal changes in the AMOC and its associated horizontal heat transport are to a large degree responsible for this predictability. 


\section{Predictability of Decadal Atlantic Meridional Overturning Circulation Variations}

This attribution raises the question of the predictability of the AMOC. This question is difficult to address because of the historical paucity of direct measurements of the AMOC. The RAPID array at $26^{\circ} \mathrm{N}$ has been in place for 13 years (at the time of writing), and therefore direct validation of decadal forecasts will soon be a possibility, albeit with low statistical confidence. For the near to medium-term future, we will be reliant on ocean reanalyses (also known as ocean syntheses), which provide a dynamically consistent ocean state constrained to be as close to observations as possible. These ocean reanalyzes or syntheses therefore provide AMOC estimates (which can themselves be validated against observations at $26^{\circ} \mathrm{N}$ ) for a far longer period than is possible using the RAPID array. While the differences were not as high as with SST or upper-ocean heat content, Pohlmann et al. (2013) demonstrated using a multimodel approach that initialized decadal prediction systems were better at predicting AMOC estimates from the GECCO ocean synthesis than persistence. There is a far wider variety of ocean syntheses now available and comparisons among them will give a better idea of the actual variation of the AMOC, with estimated uncertainty bounds from the mid-20th century onward.

\section{Continued Development of State-of-the-Art Prediction Systems}

Meehl et al. (2014) provided a useful summary of decadal prediction systems that contributed to the CMIP5 (Coupled Model Intercomparison Project phase 5) decadal prediction experiments. At the time of that review, many of the groups had not published individual accounts of their latest results, but in the intervening period they have been published (Knight et al., 2014; Msadek et al., 2014; Wu et al., 2015). Interesting recent uses and advances include work by García-Serrano et al. (2015) on predictability of the AMO, by Müller et al. (2014) extending decadal predictions as far back as 1901, and by Timmreck et al. (2016) suggesting that volcanic aerosols play a more important role than previously thought, including over European land areas. Potential advances in forecasting techniques are discussed by, for example, Mochizuki et al. (2016), on four-dimensional variational data assimilation, and Smith et al. (2016), who discussed the benefits of improved vertical resolution of the stratosphere as well as horizontal resolution in the atmosphere and ocean and initialization of sea ice.

A recent development is the extension of the scope of decadal prediction beyond atmospheric temperature to include a larger number of societally relevant variables, such as soil moisture, vegetation, and wildfire (Chikamoto et al., 2015), sea ice (Germe et al., 2014; Huang et al., 2015), salinity (Huang et al., 2015), windstorm activity (Nissen et al., 2014), precipitation over land (e.g., Rodríguez-Fonseca et al., 2015, on West African drought), and North Atlantic circulation (Smith et al., 2016).

\section{Summary and Conclusions}




\section{Predictability of Decadal Atlantic Meridional Overturning Circulation Variations}

In our changing climate, there is an increasing societal demand to predict climatic variations for well-planned mitigation and cost-efficient adaptation. On interannual to decadal timescales, accurate prediction of global atmospheric temperature comes from the correct estimation of the internal variability, rather than the exact future $\mathrm{CO}_{2}$ emission pathway (Figure 1, left). On timescales longer than decades, the main signature of internal variability is located in the North Atlantic region (Figure 1, right), with a pattern typical of SAT variations associated with AMOC changes (Drijfhout, 2015). Hence, decadal AMOC variations appear to be a key factor for prediction of the atmospheric temperature on decadal timescales. From a physical point of view, because of its northward heat transport, the AMOC is central to the climatic system of the North Atlantic and its neighboring regions. This article describes and discusses state-of-the-art knowledge on the decadal variability and predictability of this large-scale ocean circulation.

Two paradigms (stochastic and deterministic) explain the difficulty of predicting the climate system. For both paradigms, an idealized model is used to illustrate how external or internal processes lead to uncertainty in climate prediction. As always, in the real climate system, the truth lies in the middle. This means that both sources of uncertainty limit our ability to predict the climate on decadal timescales.

There are both contributing and limiting factors for decadal predictability of the AMOC. Contributing factors can be divided into two types: modes of variability and precursors. The former suggests that harmonic variations, that recur with a well-established period, contribute to accurate predictions. In the same manner, determining precursors, and using them as early warning signals for AMOC changes increases our ability to predict the system. In addition, the mechanisms that lead to uncertainty in climate prediction have been described through both theoretical and pragmatic investigations.

Finally, regarding the state of the art of AMOC prediction on interannual to decadal timescales, the article addresses decadal prediction systems and the use of data assimilation to accurately constrain the initial conditions. The latter induces a current challenge for prediction systems. Indeed, because of the inherent mismatch between the natural states of the models used for prediction and the (mostly oceanic) observations used to constrain their initial conditions, there are strong drifts during prediction that need to be corrected. The drifts are linked to the recovery of numerical models from their observation-constrained attractor to their inherent attractor during the unconstrained prediction phase. The article also includes a brief review of future developments in climate prediction, such as new techniques to avoid strong drifts, and also the extension of the scope of predictions to other climatically relevant variables, such as sea ice, storm activity, and precipitation over land.

The topic of predictability is extremely dense and only a few methods are described here. For example, there is another method that diagnoses predictability based on long model control simulations (see Branstator \& Teng, 2012, 2014; DelSole \& Tipett, 2009). This method is particularly efficient since it does not require new simulations and takes 


\section{Predictability of Decadal Atlantic Meridional Overturning Circulation Variations}

advantage of already existing ones. However, the assumption that the level of variability is constant is central to the method and remains an inherent shortcoming in a changing climate. Another existing method is the best analogues approach, which, after identifying past climate states close to the current one, assesses the likely future evolution of the climate based on typical outcomes of the close climate states (Barnett \& Preisendorfer, 1978). On a more theoretical level, Pullback Attractor (Chekroun et al., 2010; Ghil et al., 2008; Sévellec \& Fedorov, 2015B; Pierini et al., 2016) and Transfer Operator (Tantet et al., 2015) methods, although they have not yet been applied to state-of-the-art climate models, already demonstrate promising results for the characterization of predictability.

AMOC predictability is intrinsically linked to climate predictability on decadal timescales. However, the former remains poorly quantitatively assessed, with as yet no consensus in the scientific community. Since the technical expertise required for accurate quantitative prediction goes beyond the confines of climate science, significant advancements are likely to come from future methodological and/or computational-power breakthroughs.

\section{Acknowledgments}

This research was supported by the Natural and Environmental Research Council UK (MESO-CLIP, NE/K005154/1, ACSIS NE/N018044/1, SMURPHS, NE/N005767/1, and NE/ N005686/1) and the HEIF (Higher Education Innovation Fund) Research Collaboration Stimulus Fund from Southampton Marine and Maritime Institute (SYCLOPE). The authors acknowledge the World Climate Research Programme Working Group on Coupled Modelling, which is responsible for CMIP, and we thank the climate modeling groups for producing and making available their model output (see Appendix A). For CMIP, the U.S. Department of Energy's Program for Climate Model Diagnosis and Intercomparison provided coordinating support and led development of software infrastructure in partnership with the Global Organization for Earth System Science Portals.

\section{References}

Anderson, D. L. T., et al. (2007). Development of the ECMWF seasonal forecast system. Tech. rep., European Centre for Medium-Range Weather Forecasting.

Arzel, O., Colin de Verdière, A., \& England, M. H. (2010). The role of oceanic heat transport and wind stress forcing abrupt millennial-scale climate transitions. Journal of Climate, 23, 2233-2256.

Baehr, J., \& Piontek, R. (2014). Ensemble initialization of the oceanic component of a coupled model through bred vectors at seasonal-to-interannual timescales. Geoscientific Model Development, 7, 453-461. 


\section{Predictability of Decadal Atlantic Meridional Overturning Circulation Variations}

Balmaseda, M. A., Trenberth, K. E., \& Källén, E. (2013). Distinctive climate signals in reanalysis of global ocean heat content. Geophysical Research Letters, 40.

Barnett, T. P., \& Preisendorfer, R. W. (1978). Multifield analog prediction of short-term climate fluctuations using a climate state vector. Journal of Atmospheric Science, 35, 1771-1787.

Barreiro, M., et al. (2008). Abrupt climate changes: How freshening of the Northern Atlantic affects the thermohaline and wind-driven oceanic circulations. Annual Review of Earth and Planetary Sciences, 36, 33-58.

Belkin, I. S., et al. (1998). Great salinity anomalies in the North Atlantic. Progress in Oceanography, 41, 1-68.

Ben Jelloul, M., \& Huck, T. (2003). Basin-mode interactions and selection by the mean flow in a reduced-gravity quasigeostrophic model. Journal of Physical Oceanography, 33, 2320-2332.

Ben Jelloul, M., \& Huck, T. (2005). Low-frequency basin modes in a two-layer quasigeostrophic model in the presence of a mean gyre flow. Journal of Physical Oceanography, 33, 2167-2185.

Boer, G. J. (2000). A study of atmosphere-ocean predictability on long time scales. Climate Dynamics, 16, 469-477.

Boer, G. J. (2004). Long time-scale potential predictability in an ensemble of coupled climate models. Climate Dynamics, 23, 29-44.

Boer, G. J. (2011). Decadal potential predictability of twenty-first century climate. Climate Dynamics, 36, 1119-1133.

Boer, G. J., Kharin, V. V., \& Merryfield, W. J. (2013). Decadal predictability and forecast skill. Climate Dynamics, 41, 1817-1833.

Bond, G., et al. (1997). A pervasive millennial-scale cycle in North Atlantic Holocene and glacial climates. Science, 278, 1257-1266.

Bond, G., et al. (1999). The North Atlantic's 1-2 kyr climate rhythm: Relation to Heinrich events, Dansgaard-Oeschger events, and the Little Ice Age. Geophysical Monograph Series, 112, 35-58.

Branstator, G., \& Teng, H. (2012). Potential impact of initialization on decadal predictions as assessed for CMIP5 models. Geophysical Research Letters, 39, L12 703.

Branstator, G., \& Teng, H. (2014). Is AMOC more predictable than North Atlantic heat content? Journal of Climate, 27, 3537-3550. 


\section{Predictability of Decadal Atlantic Meridional Overturning Circulation Variations}

Bryden, H. L., et al. (2014). Impact of a 30\% reduction in Atlantic meridional overturning during 2009-2010. Ocean Science, 10, 683-691.

Buckley, M. W., \& Marshall, J. (2016). Observations, inferences, and mechanisms of the Atlantic meridional overturning circulation: A review. Reviews of Geophysics, 54, 5-63.

Buckley, M. W., et al. (2012). On the relationship between decadal buoyancy anomalies and variability of the Atlantic meridional overturning circulation. Journal of Climate, 25, 8009-8030.

Bugnion, V., \& Hill, C. (2006). Equilibration mechanisms in an adjoint ocean general circulation model. Ocean Dynamics, 56, 51-61.

Cessi, P., \& Paparella, F. (2001). Excitation of basin modes by ocean-atmosphere coupling. Geophysical Research Letters, 28, 2437-2440.

Chang, J., et al. (2004). Predictability of linear coupled systems. Part I: Theoretical analyses. Journal of Climate, 17, 1474-1486.

Chekroun, M., Simonnet, E., \& Ghil, M. (2010). Stochastic climate dynamics: Random attractor and time-dependent invariant measures. Journal of Physics $D$, in revision.

Chen, F., \& Ghil, M. (1995). Interdecadal variability of the thermohaline circulation and high-latitude surface flux. Journal of Physical Oceanography, 25, 2547-2568.

Cheng, W., Bleck, R., \& Rooth, C. (2004). Multi-decadal thermohaline variability in an ocean-atmosphere general circulation model. Climate Dynamics, 22, 573-590.

Cheng, W., Chiang, J. C. H., \& Zhang, D. (2013). Atlantic meridional overturning circulation (AMOC) in CMIP5 models: RCP and historical simulations. Climate Dynamics, 26, 7187-7197.

Chikamoto, Y., et al. (2015). Decadal predictability of soil water, vegetation, and wildfire frequency over North America. Climate Dynamics, 45, 2213-2235.

Choudhury, D., et al. (2016). Sampling biases in CMIP5 decadal forecasts. Journal of geophysical research. Atmospheres, 121, 3435-3445.

Cimatoribus, A. A., et al. (2012). Sensitivity of the Atlantic meridional overturning circulation to South Atlantic freshwater anomalies. Climate Dynamics, 39, 2291-2306.

Cimatoribus, A. A., et al. (2013). Dansgaard-Oeschger events: Bifurcation points in the climate system. Climate of the Past, 9, 323-333.

Colin de Verdière, A. (2007). A simple model of millennial oscillations of the thermohaline circulation. Journal of Physical Oceanography, 37, 1142-1155. 


\section{Predictability of Decadal Atlantic Meridional Overturning Circulation Variations}

Colin de Verdière, A., \& Huck, T. (1999). Baroclinic instability: An oceanic wavemaker for interdecadal variability. Journal of Physical Oceanography, 29, 893-910.

Colin de Verdière, A., \& te Raa, L. (2010). Weak oceanic heat transport as a cause of the instability of glacial climates. Climate Dynamics, 35, 1237-1256.

Collins, M. (2002). Climate predictability on interannual to decadal time scales: The initial value problem. Climate Dynamics, 19, 671-692.

Collins, M., \& Sinha, B. (2003). Predictability of decadal variations in the thermohaline circulation and climate. Geophysical Research Letters, 30, 1306.

Collins, M., et al. (2006). Interannual to decadal climate predictability in the North Atlantic: A multimodel-ensemble study. Journal of Climate, 19, 1195-1203.

Counillon, F., et al. (2014). Seasonal-to-decadal predictions with the ensemble Kalman filter and the Norwegian Earth System Model: A twin experiment. Tellus, 66, 21074.

Czeschel, L., Marshall, D. P., \& Johnson, H. L. (2010). Oscillatory sensitivity of Atlantic overturning to high-latitude forcing. Geophysical Research Letters, 37, L10 601.

Dakos, V., et al. (2008). Slowing down as an early warning signal for abrupt climate change. Proceedings of the National Academy of Sciences of the United States of America, 105(14), 308-312.

Danabasoglu, G. (2008). On multidecadal variability of the Atlantic meridional overturning circulation in the community climate system model version 3. Journal of Climate, 21, 5524-5544.

Dansgaard, W., et al. (1993). Evidence for general instability of past climate from a 250kyr ice-core record. Nature, 364, 218-220.

DelSole, T., \& Tipett, M. K. (2009). Average predictability time. Part II: Seamless diagnosis of predictability on multiple time scales. Journal of Atmospheric Science, 66, 1172-1187.

Delworth, T. L., \& Mann, M. E. (2000). Observed and simulated multidecadal variability in the northern hemisphere. Climate Dynamics, 16, 661-676.

Deshayes, J., Straneo, F., \& Spall, M. A. (2009). Mechanisms of variability in a convective basin. Journal of Marine Research, 67, 273-303.

Dewar, W. K., \& Huang, R. X. (1995). Fluid flow in loops driven by freshwater and heat fluxes. Journal of Fluid Mechanics, 297, 153-191.

Dewar, W. K., \& Huang, R. X. (1996). On a forced flow of salty water in a loop. Physics of Fluids, 4, 954-970. 


\section{Predictability of Decadal Atlantic Meridional Overturning Circulation Variations}

Dijkstra, H. A. (2007). Characterization of the multiple equilibria regime in a global ocean model. Tellus, 59A, 695-705.

Dijkstra, H. A. (2013). Nonlinear climate dynamics. Cambridge: Cambridge University Press.

Dijkstra, H. A., \& Ghil, M. (2005). Low-frequency variability of the large-scale ocean circulation: A dynamical systems approach. Reviews of Geophysics, 43, RG3002.

Dijkstra, H. A., et al. (2006). On the physics of the Atlantic multidecadal oscillation. Ocean Dynamics, 56, 36-50.

Doblas-Reyes, F. J., et al. (2011). Decadal climate prediction with the ECMWF coupled forecast system: Impact of ocean observations. Journal of Geophysical Research, 116, D19 111.

Dong, B., \& Sutton, R. T. (2005). Mechanism of interdecadal thermohaline circulation variability in a coupled ocean-atmosphere GCM. Journal of Climate, 18, 1117-1135.

D'Orgeville, M., \& Peltier, W. R. (2009). Implications of both statistical equilibrium and global warming simulations with CCSM3. Part II: On the multidecadal variability in the North Atlantic basin. Journal of Climate, 22, 5298-5318.

Drijfhout, S. (2015). Competition between global warming and an abrupt collapse of the AMOC in Earth's energy imbalance. Scientific Report, 5, 14877.

Drijfhout, S., van Oldenborgh, G. J., \& Cimatoribus, A. (2012). Is a decline of AMOC causing the warming hole above the North Atlantic in observed and modeled warming patterns? Journal of Climate, 25, 8373-8379.

$\mathrm{Du}, \mathrm{H}$., et al. (2012). Sensitivity of decadal predictions to the initial atmospheric and oceanic perturbations. Climate Dynamics, 39, 2013-2023.

Dunstone, N. J., \& Smith, D. M. (2010). Impact of atmosphere and sub-surface ocean data on decadal climate prediction. Geophysical Research Letters, 37, L02 709.

Eade, R., et al. (2014). Do seasonal-to-decadal climate predictions under-estimate the predictability of the real world? Geophysical Research Letters, 41, 5620-5628.

Enfield, D. B., Mestas-Nunez, A. M., \& Trimble, P. J. (2001). The Atlantic multidecadal oscillation and its relation to rainfall and river flows in the continental U.S. Geophysical Research Letters, 28, 2077-2080.

Farrell, B. F., \& Ioannou, P. J. (1996a). Generalized stability theory. Part I: Autonomous operators. Journal of Atmospheric Science, 35, 2025-2040.

Farrell, B. F., \& Ioannou, P. J. (1996b). Generalized stability theory. Part II:

Nonautonomous operators. Journal of Atmospheric Science, 53, 2041-2053. 


\section{Predictability of Decadal Atlantic Meridional Overturning Circulation Variations}

Farrell, B. F., \& Ioannou, P. J. (2001). Accurate low-dimensional approximation of the linear dynamics of fluid flow. Journal of Atmospheric Science, 58, 2771-2789.

Frankcombe, L. M., \& Dijkstra, H. A. (2009). Coherent multidecadal variability in North Atlantic sea level. Geophysical Research Letters, 36, L15 604.

Frankcombe, L. M., Dijkstra, H. A., \& von der Heydt, A. (2008). Sub-surface signatures of the Atlantic multidecadal oscillation. Geophysical Research Letters, 35, L19 602.

Frankignoul, C., \& Hasselmann, K. (1977). Stochastic climate models, part II. Application to sea-surface temperature anomalies and thermocline variability. Tellus, 29, 289-305.

García-Serrano, J., et al. (2015). On the predictability of the winter Euro-Atlantic climate: Lagged influence of autumn Arctic sea ice. Journal of Climate, 28, 5195-5216.

Germe, A., et al. (2014). Interannual predictability of Arctic sea ice in a global climate model: Regional contrasts and temporal evolution. Climate Dynamics, 43, 2519-2538.

Germe, A., et al. (2017). On the robustness of near term climate predictability regarding initial state uncertainties. Climate Dynamics, 48, 353-366.

Ghil, M., Chekroun, M., \& Simonnet, E. (2008). Climate dynamics and fluid mechanics: Natural variability and related uncertainties. Journal of Physics D, 237, 2111-2126.

Goldenberg, S. B., et al. (2001). The recent increase in Atlantic hurricane activity: Causes and implications. Nature, 293, 474-479.

Gordon, A. L. (1986). Interocean exchange of thermocline water. Journal of Physical Oceanography, 91, 5037-5046.

Griffies, S. M., \& Bryan, K. (1997). A predictability study of simulated North Atlantic multidecadal variability. Climate Dynamics, 13, 459-487.

Grootes, P. M., \& Stuiver, M. (1997). Oxygen 18/16 variability in Greenland snow and ice with 10-3 to 105-year time resolution. Journal of Geophysical Research, 102(26), 455470.

Guemas, V., et al. (2014). Ensemble of sea ice initial conditions for interannual climate predictions. Climate Dynamics, 43, 2813-282.

Haak, H., et al. (2003). Formation and propagation of great salinity anomalies.

Geophysical Research Letters, 30, GL017 065.

Hasselmann, K. (1976). Stochastic climate models Part I. Theory. Tellus, 28, 473-485.

Hawkins, E., \& Sutton, R. (2009a). Decadal predictability of the Atlantic Ocean in a coupled GCM: Forecast skill and optimal perturbations using linear inverse modeling. Journal of Climate, 22, 3960-3978. 


\section{Predictability of Decadal Atlantic Meridional Overturning Circulation Variations}

Hawkins, E., \& Sutton, R. (2009b). The potential to narrow uncertainty in regional climate predictions. Bulletin of the American Meteorological Society, 90, 1095-1107.

Hawkins, E., \& Sutton, R. (2011). Estimating climatically relevant singular vectors for decadal predictions of the Atlantic Ocean. Journal of Climate, 24, 109-123.

Hazeleger, W., et al. (2013). Predicting multiyear North Atlantic Ocean variability. Journal of Geophysical Research, 118, 1087-1098.

Heimbach, P., et al. (2011). Timescales and regions of the sensitivity of Atlantic meridional volume and heat transport: Toward observing system design. Deep Sea Research Part II: Topical Studies in Oceanography, 58, 1858-1879.

Howard, L. N. (1971). ABC's of convection. Geophysical Fluid Dynamics Summer School. Tech. rep., 71-63, 102-105, WHOI internal report.

Huang, B., et al. (2015). Climate drift of AMOC, North Atlantic salinity and arctic sea ice in CFSv2 decadal predictions. Climate Dynamics, 44, 559-583.

Huang, R. X., \& Dewar, W. K. (1996). Haline circulation: Bifurcation and chaos. Journal of Physical Oceanography, 26, 2093-2106.

Huck, T., Colin de Verdière, A., \& Weaver, A. J. (1999). Interdecadal variability of the thermohaline circulation in box-ocean models forced by fixed surface fluxes. Journal of Physical Oceanography, 29, 865-892.

Huck, T., \& Vallis, G. K. (2001). Linear stability analysis of three-dimensional thermallydriven ocean circulation: Application to interdecadal oscillations. Tellus, 53A, 526-545.

Huisman, S. E., den Toom, M., \& Dijkstra, H. A. (2010). An indicator of the multiple equilibria regime of the Atlantic meridional overturning circulation. Journal of Physical Oceanography, 40, 551-567.

Hurrell, J., et al. (2006). Atlantic climate variability and predictability: A CLIVAR perspective. Journal of Climate, 19, 5100-5121.

Häkkinen, S. (1999) A simulation of thermohaline effects of a great salinity anomaly. Journal of Climate, 12, 1781-1795.

Ioannou, P. J. (1995). Nonnormality increases variance. Journal of Atmospheric Science, 52, 1155-1158.

IPCC. (2013). Climate change 2013-The physical science basis: Contribution of Working Group I to the Fifth Assessment Report of the IPCC. Cambridge, UK: Cambridge University Press.

Iwi, A. M., et al. (2012). Mechanisms linking volcanic aerosols to the Atlantic meridional overturning circulation. Journal of Climate, 25, 3039-3051. 


\section{Predictability of Decadal Atlantic Meridional Overturning Circulation Variations}

Jackson, L. C., et al. (2015). Global and European climate impacts of a slowdown of the AMOC in a high resolution GCM. Climate Dynamics, 45, 3299-3316.

Jones, G. S., et al. (2005). An AOGCM simulation of the response to a volcanic supereruption. Climate Dynamics, 25, 725-738.

Karspeck, A., et al. (2013). An ensemble adjustment Kalman filter for the ocean component of CCSM4. Journal of Climate, 26, 7392-7413.

Keenlyside, N. S., et al. (2008). Advancing decadal-scale climate prediction in the North Atlantic sector. Nature, 453, 84-88.

Knight, J. R., Folland, C. K., \& Scaife, A. A. (2006). Climate impacts of the Atlantic multidecadal oscillation. Geophysical Research Letters, 33, L17 706.

Knight, J. R., et al. (2005). A signature of persistent natural thermohaline circulation cycles in observed climate. Geophysical Research Letters, 32, L20 708.

Knight, J. R., et al. (2014). Predictions of climate several years ahead using an improved decadal prediction system. Journal of Climate, 27, 7550-7567.

Kumar, A., Peng, P., \& Chen, M. (2014). Is there a relationship between potential and actual skill? Monthly Weather Review, 142, 2220-2227.

Kushnir, Y. (1994). Interdecadal variations in North Atlantic sea surface temperature and associated atmospheric conditions. Journal of Climate, 7, 141-157.

Latif, M. (1997). Dynamics of interdecadal variability in coupled ocean-atmosphere models. Journal of Climate, 11, 602-624.

Latif, M., et al. (2006). A review of predictability studies of Atlantic sector climate on decadal time scales. Journal of Climate, 19, 5971-5986.

Latif, M., et al. (2007). Decadal to multidecadal variability of the Atlantic MOC: Mechanisms and predictability. AGU Monograph, 173, 149-166.

Lenton, T. M. (2011). Early warning of climate tipping points. Nature Climate Change, 1, 201-209.

Livina, V. N., \& Lenton, T. M. (2007). A modified method for detecting incipient bifurcations in a dynamical system. Geophysical Research Letters, 34, L03 712.

Lorenz, E. N. (1963). Deterministic non-periodic flow. Journal of Atmospheric Science, 20, 130-141.

Lorenz, E. N. (1965). Predictability study of 28-variable atmospheric model. Tellus, 3, 321-333. 


\section{Predictability of Decadal Atlantic Meridional Overturning Circulation Variations}

Madec, G. (2008). NEMO ocean engine. Tech. rep., Institut Pierre-Simon Laplace (IPSL), France, No27.

Malkus, W. V. R. (1972). Non-periodic convection at high and low Prandtl number. Mémoires Société Royale des Sciences de Liège, 6e Serie, Tome IV, 125-128.

Marotzke, J., \& Willebrand, J. (1991). Multiple equilibria of the global thermohaline circulation. Journal of Physical Oceanography, 21, 1372-1385.

Marotzke, J., et al. (1999). Construction of the adjoint MIT ocean general circulation model and application to Atlantic heat transport sensitivity. Journal of Geophysical Research, 104, 529-548.

Marshall, J., Johnson, H., \& Goodman, J. (2001). A study of the interaction of the North Atlantic oscillation with ocean circulation. Journal of Climate, 14, 1399-1421.

Matei, D., et al. (2012). Multiyear prediction of monthly mean Atlantic meridional overturning circulation at $26.5^{\circ} \mathrm{N}$. Science, $335,76-79$.

McCarthy, G., et al. (2012). Observed interannual variability of the Atlantic meridional overturning circulation at 26.5 N. Geophysical Research Letters, 39, L19 609.

Meehl, G. A., Teng, H., \& Arblaster, J. M. (2014). Climate model simulations of the observed early-2000s hiatus of global warming. Nature Climate Change, 4, 898-902.

Meehl, G. A., et al. (2009). Decadal prediction: Can it be skillful? Bulletin of the American Meteorological Society, 90, 1467-1485.

Meehl, G. A., et al. (2015). Decadal climate prediction: An update from the trenches. Bulletin of the American Meteorological Society, 95, 243-267.

Mignot, J., et al. (2011). Volcanic impact on the Atlantic Ocean over the last millennium. Climate of the Past, 7, 1439-1455.

Mills, M. J., et al. (2016). Global volcanic aerosol properties derived from emissions, 1990-2014, using CESM1 (WACCM). Journal of Geophysical Research: Atmospheres, 121, 2332-2348.

Mochizuki, T., et al. (2016). Multiyear climate prediction with initialization based on 4DVardata assimilation. Geophysical Research Letters, 43, 3903-3910.

Moore, A. M., et al. (2003). The role of air-sea interaction in controlling the optimal perturbations of low-frequency tropical coupled ocean-atmosphere modes. Journal of Climate, 16, 951-968.

Msadek, R., \& Frankignoul, C. (2009). Atlantic multidecadal oceanic variability and its influence on the atmosphere in a climate model. Climate Dynamics, 33, 45-62. 


\section{Predictability of Decadal Atlantic Meridional Overturning Circulation Variations}

Msadek, R., et al. (2010). Assessing the predictability of the Atlantic meridional overturning circulation and associated fingerprints. Geophysical Research Letters, 37, L19 608.

Msadek, R., et al. (2014). Importance of initial conditions in seasonal predictions of Arctic sea ice extent. Geophysical Research Letters, 41, 5208-5215.

Mu, M., Sun, L., \& Dijkstra, H. A. (2004). The sensitivity and stability of the ocean's thermohaline circulation to finite amplitude perturbations. Journal of Physical Oceanography, 45, 2305-2315.

Muir, L. C., \& Fedorov, A. V. (2017). Evidence of the AMOC interdecadal mode related to westward propagation of temperature anomalies in CMIP5 models. Climate Dynamics, 48, 1517-1535.

Müller, W. A., et al. (2014). Decadal climate predictions for the period 1901-2010 with a coupled climate model. Geophysical Research Letters, 41, 2100-2107.

Narapusetty, B., Stan, C., \& Kumar, A. (2014). Bias correction methods for decadal seasurface temperature forecasts. Tellus, 66(23), 681.

Nissen, K. M., et al. (2014). Decadal windstorm activity in the North Atlantic-European sector and its relationship to the meridional overturning circulation in an ensemble of simulations with a coupled climate model. Climate Dynamics, 43, 1545-1555.

Ortega, P., et al. (2015). Reconciling two alternative mechanisms behind bi-decadal AMOC variability. Progress in Oceanography, 137, 237-249.

Oterrå, O. H., et al. (2010). External forcing as a metronome for Atlantic multidecadal variability. Nature Geoscience, 3, 688-694.

Palmer, T. N. (1999). A nonlinear dynamical perspective on climate prediction. Journal of Climate, 12, 575-591.

Pausata, F. S. R., et al. (2015). Impacts of high-latitude volcanic eruptions on ENSO and AMOC. Proceedings of the National Academy of Sciences of the United States of America, 112(13), 784-788.

Persechino, A., et al. (2013). Decadal predictability of the Atlantic meridional overturning circulation and climate in the IPSL-CM5A-LR model. Climate Dynamics, 40, 2359-2380.

Pierini, S., Ghil, M., \& Chekroun, M. D. (2016). Exploring the pullback attractors of a loworder quasigeostrophic ocean model: The deterministic case. Journal of Physical Oceanography, 29, 4185-4202.

Pohlmann, H., et al. (2004). Estimating the decadal predictability of coupled AOGCM. Journal of Climate, 17, 4463-4472. 


\section{Predictability of Decadal Atlantic Meridional Overturning Circulation Variations}

Pohlmann, H., et al. (2009). Initializing decadal climate predictions with the GECCO oceanic synthesis: Effects on the North Atlantic. Journal of Climate, 22, 3926-3938.

Pohlmann, H., et al. (2013). Predictability of the mid-latitude Atlantic meridional overturning circulation in a multi-model system. Climate Dynamics, 40, 775-785.

Rahmstorf, S. (1995). Bifurcation of the Atlantic thermohaline circulation in response to changes in the hydrological cycle. Nature, 378, 145-149.

Rahmstorf, S. (2000). The thermohaline ocean circulation-A system with dangerous threshold? Climatic Change, 46, 247-256.

Rahmstorf, S., et al. (2005). Thermohaline circulation hysteresis: a model intercomparison. Geophysical Research Letters, 32, L23 605.

Rahmstorf, S., et al. (2015). Exceptional twentieth-century slowdown in Atlantic Ocean overturning circulation. Nature Climate Change, 5, 475-480.

Ramanova, V., \& Hense, A. (2015). Anomaly transform methods based on total energy and ocean heat content norms for generating ocean dynamic disturbances for ensemble climate forecasts. Climate Dynamics.

Roberts, C. D., et al. (2015). Quantifying the likelihood of a continued hiatus in global warming. Nature Climate Change, 5, 337-342.

Robson, J., Sutton, R., \& Smith, D. (2012a). Initialized decadal predictions of the rapid warming of the North Atlantic Ocean in the mid 1990s. Geophysical Research Letters, 39, L19 713.

Robson, J., Sutton, R., \& Smith, D. (2014a). Decadal predictions of the cooling and freshening of the North Atlantic in the 1960s and the role of ocean circulation. Climate Dynamics, 42, 2353-2365.

Robson, J., et al. (2012b). Causes of the rapid warming of the North Atlantic Ocean in the mid-1990s. Journal of Climate, 25, 4116-4134.

Robson, J., et al. (2014b). Atlantic overturning in decline? Nature Geoscience, 7, 2-3.

Robson, J., et al. (2017). Decadal prediction of the North Atlantic subpolar gyre in the HiGEM high-resolution climate model. Climate Dynamics, in press.

Rodríguez-Fonseca, B., et al. (2015). Variability and predictability of West African droughts: A review on the role of sea surface temperature anomalies. Journal of Climate, $28,4034-4060$.

Roscoe, H. K. (2001). The risk of large volcanic eruptions and the impact of this risk on future ozone depletion. Natural Hazards, 23, 231-246. 


\section{Predictability of Decadal Atlantic Meridional Overturning Circulation Variations}

Sakai, K., \& Peltier, W. R. (1999). A dynamical systems model of the Dansgaard-Oeschger oscillation and the origin of the Bond cycle. Journal of Climate, 12, 2238-2255.

Sanchez-Gomez, E., et al. (2016). Drift dynamics in a coupled model initialized for decadal forecasts. Climate Dynamics, 46, 1819-1840.

Scheffer, M., et al. (2009). Early-warning signals for critical transitions. Nature, 461, 5359.

Schlesinger, M. E., \& Ramankutty, N. (1994). An oscillation in the global climate system of period 65-70 years. Nature, 367, 723-726.

Schneider, T., \& Griffies, S. M. (1999). A conceptual framework for predictability studies. Journal of Climate, 12, 3133-3155.

Sévellec, F., Ben Jelloul, M., \& Huck, T. (2007). Optimal surface salinity perturbations influencing the thermohaline circulation. Journal of Physical Oceanography, 37, 27892808.

Sévellec, F., \& Fedorov, A. V. (2013a). The leading, interdecadal eigenmode of the Atlantic meridional overturning circulation in a realistic ocean model. Journal of Climate, 26 , 2160-2183.

Sévellec, F., \& Fedorov, A. V. (2013b). Model bias reduction and the limits of oceanic decadal predictability: Importance of the deep ocean. Journal of Climate, 26, 3688-3707.

Sévellec, F., \& Fedorov, A. V. (2014). Millennial variability in an idealized ocean model: Predicting the AMOC regime shifts. Journal of Climate, 27, 3551-3564.

Sévellec, F., \& Fedorov, A. V. (2015a). Optimal excitation of AMOC decadal variability: Links to the subpolar ocean. Progress in Oceanography, 132, 287-304.

Sévellec, F., \& Fedorov, A. V. (2015b). Unstable AMOC during glacial intervals and millennial variability: The role of mean sea ice extent. Annual Review of Earth and Planetary Sciences, 429, 60-68.

Sévellec, F., \& Fedorov, A. V. (2017). Predictability and decadal variability of the North Atlantic Ocean state evaluated from a realistic ocean model. Journal of Climate, 30, 477498.

Sévellec, F., \& Huck, T. (2015). Theoretical investigation of the Atlantic multidecadal oscillation. Journal of Physical Oceanography, 45, 2189-2208.

Sévellec, F., Huck, T., \& Colin de Verdière, A. (2010). From centennial to millennial oscillation of the thermohaline circulation. Journal of Marine Research, 68, 723-742.

Sévellec, F., Sinha, B., \& Skliris, N. (2016). The rogue nature of hiatuses in a global warming climate. Geophysical Research Letters, 43, 8169-8177. 


\section{Predictability of Decadal Atlantic Meridional Overturning Circulation Variations}

Sévellec, F., et al. (2008). Optimal surface salinity perturbations of the meridional overturning and heat transport in a global ocean general circulation model. Journal of Physical Oceanography, 38, 2739-2754.

Sévellec, F., et al. (2009). Nonnormal multidecadal response of the thermohaline circulation induced by optimal surface salinity perturbations. Journal of Physical Oceanography, 39, 852-872.

Slingo, J., \& Palmer, T. (2011). Uncertainty in weather and climate prediction. Philosophical Transactions of the Royal Society A, 369, 4751-4767.

Sluka, T. C., Penny, E., Kalnay, S. G., \& Miyoshi, T. (2016). Assimilating atmospheric observations into the ocean using strongly coupled ensemble data assimilation. Geophysical Research Letters, 43, 752-759.

Smeed, D. A., et al. (2014). Observed decline of the Atlantic meridional overturning circulation 2004 to 2012. Ocean Science, 10, 29-38.

Smith, D. M., et al. (2007). Improved surface temperature prediction for the coming decade from a global climate model. Science, 317, 796-799.

Smith, D. M., et al. (2010). Skilful multi-year predictions of Atlantic hurricane frequency. Nature Geoscience, 3, 846-849.

Smith, D. M., et al. (2016). Seasonal to decadal prediction of the winter North Atlantic oscillation: Emerging capability and future prospects. Quarterly Journal of the Royal Meteorological Society, 142, 611-617.

Spall, M. A. (2008). Low-frequency interaction between horizontal and overturning gyres in the ocean. Geophysical Research Letters, 35, L18 614.

Srokosz, M., \& Bryden, H. L. (2015). Observing the Atlantic meridional overturning circulation yields a decade of inevitable surprises. Science, 348, 1330.

Srokosz, M., et al. (2012). Past, present, and future changes in the Atlantic meridional overturning circulation. Bulletin of the American Meteorological Society, 93, 1663-1676.

Stommel, H. (1958). The abyssal circulation. Deep-Sea Research, 4, 80-82.

Stommel, H. (1961). Thermohaline convection with stable regimes flow. Tellus, 13, 224230.

Strogatz, S. H. (1994). Nonlinear dynamics and chaos with applications to physics, biology, chemistry and engineering. Advanced book program, Perseus book.

Sutton, R. W., \& Hodson, D. L. R. (2003). Influence of the ocean on North Atlantic climate variability 1671-1999. Journal of Climate, 16, 3296-3313. 


\section{Predictability of Decadal Atlantic Meridional Overturning Circulation Variations}

Sutton, R. W., \& Hodson, D. L. R. (2005). Atlantic Ocean forcing of North American and European summer climate. Science, 309, 115-118.

Swingedouw, D., et al. (2013). Initialisation and predictability of the AMOC over the last 50 years in a climate model. Climate Dynamics, 40, 2381-2399.

Swingedouw, D., et al. (2015). Bidecadal North Atlantic Ocean circulation variability controlled by timing of volcanic eruptions. Nature Communications, 6, 6545.

Swingedouw, D., et al. (2017). Impact of explosive volcanic eruptions on the main climate variability modes. Global and Planetary Changes, 150, 24-45.

Tantet, A., van der Burgt, F. R., \& Dijkstra, H. A. (2015). An early warning indicator for atmospheric blocking events using transfer operators. Chaos, 25, 036406.

Tardif, R., Hakim, G. J., \& Snyder, C. (2014). Coupled atmosphere-ocean data assimilation experiments with a low-order climate model. Climate Dynamics, 43, 1631-1643.

Taylor, K. E., Stouffer, R. J., \& Meehl, G. A. (2012). An overview of CMIP5 and the experiment design. Bulletin of the American Meteorological Society, 93, 485-498.

te Raa, L. A., \& Dijkstra, H. A. (2002). Instability of the thermohaline ocean circulation on interdecadal timescales. Journal of Physical Oceanography, 32, 138-160.

Teng, H., Branstator, G., \& Meehl, G. H. (2011). Predictability of the Atlantic overturning circulation and associated surface patterns in two CCSM3 climate change ensemble experiments. Journal of Climate, 24, 6054-6076.

Thoma, M., et al. (2015). Decadal hindcasts initialized using observed surface wind stress: Evaluation and prediction out to 2024. Geophysical Research Letters, 42, 64546461.

Timmreck, C., et al. (2016). The impact of stratospheric volcanic aerosol on decadal-scale climate predictions. Geophysical Research Letters, 43, 834-842.

Tziperman, E., \& Ioannou, P. J. (2002). Transient growth and optimal excitation of thermohaline variability. Journal of Physical Oceanography, 32, 3427-3435.

Tziperman, E., Zanna, L., \& Penland, C. (2008). Nonnormal thermohaline circulation dynamics in a coupled ocean-atmosphere GCM. Journal of Physical Oceanography, 38, 588-604.

van Oldenborgh, G. J., et al. (2012). Decadal prediction skill in a multi-model ensemble. Climate Dynamics, 38, 263-1280.

Vellinga, M., \& Wood, R. A. (2002). Global climatic impacts of a collapse of the Atlantic thermohaline circulation. Climate Change, 54, 251-267. 


\section{Predictability of Decadal Atlantic Meridional Overturning Circulation Variations}

Ward, M. N. (1998). Diagnosis and short-lead time prediction of summer rainfall in tropical North Africa at interannual and multidecadal timescales. Journal of Climate, 11 , 3167-3191.

Welander, P. (1957). Note on the self-sustained oscillations of a simple thermal system. Tellus, IX, 419-420.

Welander, P. (1965). Steady and oscillatory motions of a differentially heated fluid loop. Tech. rep., 65-48, Woods Hole Oceanographic Institution.

Welander, P. (1967). On the oscillatory instability of a differentially heated fluid loop. Journal of Fluid Mechanics, 29, 17-30.

Willson, R. C. (2014). ACRIM3 and the total solar irradiance database astrophysics and space. Science, 352, 341-352.

Wu, B., et al. (2015). Initialized decadal predictions by LASG/IAP climate system model FGOALS-s2: Evaluations of strengths and weaknesses. Advances in Meteorology, Article ID 904826, $12 \mathrm{pp}$.

Wunsch, C., \& Heimbach, P. (2007). Practical global oceanic state estimation. Journal of Physics D, 230, 197-208.

Yoshimori, M., et al. (2010). Simulated decadal oscillations of the Atlantic meridional overturning circulation in a cold climate state. Climate Dynamics, 34, 101-121.

Zanna, L. (2012). Forecast skill and predictability of observed Atlantic sea surface temperatures. Journal of Climate, 25, 5047-5056.

Zanna, L., \& Tziperman, E. (2005). Nonnormal amplification of the thermohaline circulation. Journal of Physical Oceanography, 35, 1593-1605.

Zanna, L., \& Tziperman, E. (2008). Optimal surface excitation of the thermohaline circulation. Journal of Physical Oceanography, 38, 1820-1830.

Zanna, L., et al. (2011). Optimal excitation of interannual Atlantic meridional overturning circulation variability. Journal of Climate, 24, 413-427.

Zhang, R. (2007). Anticorrelated multidecadal variations between surface and subsurface tropical North Atlantic. Geophysical Research Letters, 34, L12 713.

Zhang, R., \& Vallis, G. K. (2006). Impact of great salinity anomalies on the low-frequency variability of the North Atlantic climate. Journal of Climate, 19, 470-482.

Zu, Z., M. M. \& Dijkstra, H. A. (2016). Optimal initial excitations of decadal modification of the Atlantic meridional overturning circulation under the prescribed heat and 


\section{Predictability of Decadal Atlantic Meridional Overturning Circulation Variations}

freshwater flux boundary conditions. Journal of Physical Oceanography, in press. http://

dx.doi.org/10.1175/JPO-D-15-0100.1.

\section{Appendix A: CMIP5 Multimodel Analysis}

Although original to this article, the diagnostics shown in Figure 1 follow the method of Sévellec et al. (2016). Hence, the text below is derived from Sévellec et al. with minor modifications. The analysis performed in the CMIP5 multimodel analysis followed an approach in which all the statistics were estimated from ensemble averages of 20 climate models. The SAT data for preindustrial control (with fixed present-day atmospheric GHG concentrations), historical, representative concentration pathways (RCP) 2.6, 4.5 (two "stabilization scenarios"), RCP 6.0 ("intermediate scenarios"), and RCP 8.5 ("business as usual") simulations were gathered from the CMIP5 database (Taylor et al., 2012). The 20 models are: (1) IPSL-CM5A-MR, (2) CCSM4, (3) EC EARTH, (4) GFDL-CM3, (5) MIROC5, (6) BNU-ESM, (7) CSIRO-MK3, (8) CanESM2, (9) MPI-ESM-MR, (10) INMCM4, (11) CNRM-CM5, (12) GISS-E2-R, (13) BCC-CSM1-1, (14) ACCESS1-3, (15) CMCC-CESM, (16) FGOALS-g2, (17) FIO-ESM, (18) MRI-CGCM3, (19) NorESM1-M, (20) MOHC HadGEM2ES. Except for RCP 8.5, some models were missing: for RCP 2.6, models 10, 14, and 15; for RCP 4.5, model 15; and for RCP 6.0, models 3, 4, 6, 8, 9, 10, 11, 14, 15, 16, and 18.

To evaluate the decadal internal variability, we use global SAT (i.e., a global spatial horizontal averaging of SAT) from the preindustrial control simulations for each of the 20 models. To evaluate the uncertainty of the internal variability for different prediction lead times, we first filter the global SAT using a low-pass filter with a varying cut-off frequency set between 2.5 and 80 years and based on a simple step function (i.e., removing all frequency components above the cut-off frequency but not affecting lower frequencies). Then, a probability density function of the time derivative of this filtered SAT is built to represent the standard deviation of warming and cooling events equal to or longer than cut-off frequency. This standard deviation is our measure of the internal variability for different prediction lead times and is evaluated through the 20-member multimodel mean.

For the external forcing uncertainty, we use linear trends evaluated using a linear regression of global average SAT for RCP 2.6, RCP 4.5, RCP 6.0, and RCP 8.5 at different prediction lead times. The "forced" linear trend corresponds to the 20-member multimodel mean. This allows the removal of out-of-phase internal decadal variability, hence limiting its impact on the linear trend. We chose to use a single realization for each model, and not all the different initial condition members where available, to avoid biasing our study toward the models which were run with a larger number of ensemble members. Then we compute the uncertainty in the "external" forcing by computing the interscenario variance of the multimodel-mean trend evaluated at different prediction lead times (i.e., from 2.5 to 80 years). 


\section{Predictability of Decadal Atlantic Meridional Overturning Circulation Variations}

Finally, comparing the variance of the external forcing and of the internal variability, we build the relative contribution to the total variance of external forcing and of internal variability as a function of different prediction lead times (left side of Figure 1). Assuming linearity and independence of the variances, the total variance is the sum of the variance induced by the external forcing and by the internal variability.

To compute the intensity of the local decadal internal variability we reproduce the global analysis for 10-year prediction lead time only, but at a local level (right side of Figure 1). For that we use SAT from preindustrial control simulations after linear interpolation from the respective native model grid to a regular $2^{\circ} \times 2^{\circ}$ grid. We also provide the 20 member multimodel standard deviation as a measure of the model error (Figure 7).

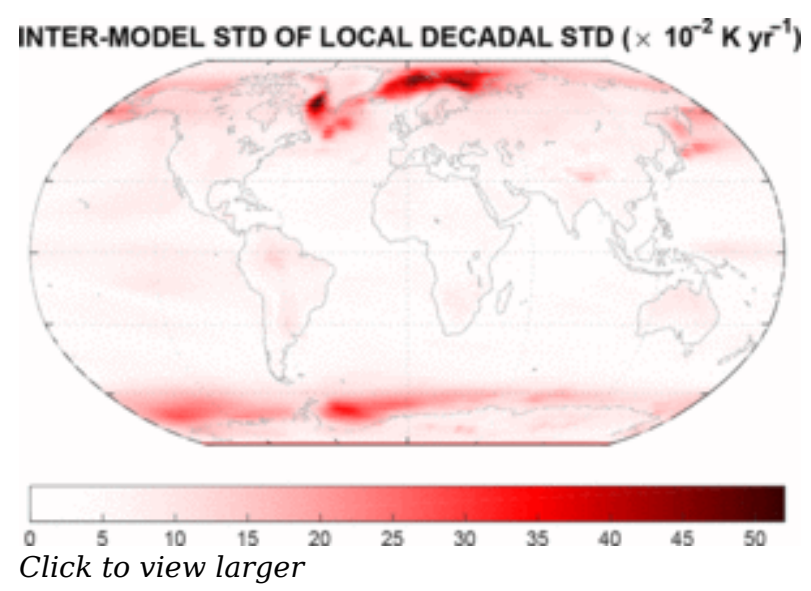

Figure 7. Multimodel standard deviation of local standard deviation of SAT decadal trend from CMIP5 preindustrial control simulations. This figure can be compared to the multimodel mean given in Figure 1, right side.

\section{Appendix B: AMO index}

To represent the AMO index we used the unsmoothed detrended AMO index from https:// esrl.noaa.gov/psd/data/timeseries/AMO/, following Enfield et al. (2001). This index is the annual mean sea-surface temperature averaged in the Atlantic from $0^{\circ} \mathrm{N}$ to $70^{\circ} \mathrm{N}$. The decadal values are obtained through a low-pass filter set at 10 years. The low- and highfrequency components are obtained by applying a bandpass filter set between 20 and 30 years and between 50 and 70 years, respectively. This procedure removes all frequency components above the maximum cut-off frequency and below the minimum cut-off frequency, leaving unaffected frequencies inside the minimum and maximum cut-off frequencies.

\section{Notes:}




\section{Predictability of Decadal Atlantic Meridional Overturning Circulation Variations}

(1.) The terms natural and internal are used here in a loose sense. Indeed, in a climate that is forced to change by unsteady anthropogenic $\mathrm{CO}_{2}$ emission, the variations around the long secular trend cannot be strictly considered natural; that is, the natural variability would be the variability of the system at statistical equilibrium. Similarly, natural variability encompasses both an internal part and a part caused by non-anthropogenic external forcing, such as volcanic eruptions or solar radiation changes.

(2.) This idea has been popularized by the idiom of the butterfly effect in the context of atmospheric circulation (Lorenz, 1963).

\section{Florian Sévellec}

University of Southampton

\section{Bablu Sinha}

University of Southampton

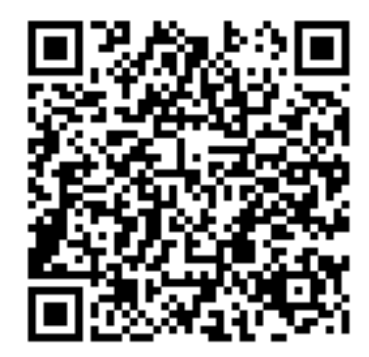

